\title{
Mathematical modelling of wave energy converters: A review of nonlinear approaches
}

\author{
Markel Penalba*, Giussepe Giorgi, John V. Ringwood \\ Centre for Ocean Energy Research, Maynooth University, Co. Kildare, Ireland
}

\section{A R T I C L E I N F O}

\section{Keywords:}

Wave energy

Nonlinear incident waves

Nonlinear power-take-off

Computational fluid dynamics

Boundary element methods

\begin{abstract}
A B S T R A C T
The wave energy sector has made and is still doing a great effort in order to open up a niche in the energy market, working on several and diverse concepts and making advances in all aspects towards more efficient technologies. However, economic viability has not been achieved yet, for which maximisation of power production over the full range of sea conditions is crucial. Precise mathematical models are essential to accurately reproduce the behaviour, including nonlinear dynamics, and understand the performance of wave energy converters. Therefore, nonlinear models must be considered, which are required for power absorption assessment, simulation of devices motion and model-based control systems. Main sources of nonlinear dynamics within the entire chain of a wave energy converter - incoming wave trains, wave-structure interaction, power take-off systems or mooring lines- are identified, with especial attention to the wave-device hydrodynamic interaction, and their influence is studied in the present paper for different types of converters. In addition, different approaches to model nonlinear wave-device interaction are presented, highlighting their advantages and drawbacks. Besides the traditional Navier-Stokes equations or potential flow methods, 'new' methods such as system-identification models, smoothed particle hydrodynamics or nonlinear potential flow methods are analysed.
\end{abstract}

\section{Introduction}

Ocean energy resources have become more important during the last decades and are now receiving worldwide attention due to the awareness of the depletion of traditional energy resources and their environmental impacts, including global warming. Wave energy may have an important role, due to its attractive potential [1], to deal with the difficult dilemma of substituting conventional energy resources towards a more sustainable energy system.

Since wave energy started to receive worldwide attention in the 1970s [2], the level of development of different technologies has grown considerably. To date, several pre-commercial devices are being tested or have already been tested in real seas. By way of example, the Wavestar [3] device has been tested at Hanstholm in 2009, the Oyster machine of Aquamarine Ltd. [4] is being tested in the European Marine Energy Centre (EMEC), in Orkney, from 2009 and the Pelamis device [5] was tested in the coast of Portugal in 2009 and in Orkney in 2010. Many other devices have been, and are being, developed around the world [6-18], with more than one thousand different prototypes developed during the last decades [19].

However, none of the existing wave energy devices has been commercially completed yet, since none have achieved economic viability. So, wave energy devices are still at an early stage of development. To be more precise, a recent study [20] describes seven different stages of Technology Readiness Levels (TRL) for wave energy devices, where the wave energy sector was placed at the beginning of TRL5 - grid connected full scale prototypes- in 2011. Although the industry has worked very hard and has progressed significantly during the last decades, much still remains to be done to achieve a fully certified commercial device recognised by an official certification body (TRL7), given the significant incremental effort required in the last stages.

In any case, even after completing this 7-step path, the wave energy industry will need to compete within the energy market against other more established technologies. In order to be competitive in the market, maximising economic return in the form of energy/electricity is required, and so maximising wave power conversion across the full range of sea states will be essential. Economic performance can be significantly assisted through the optimization of the device intelligence, suit as energy maximising control algorithms for wave energy converters. Intelligent and precise control strategies can considerably improve the performance of any wave energy device (heaving point

\footnotetext{
* Corresponding author.

E-mail address: mpenalba@eeng.nuim.ie (M. Penalba).
} 
absorbers [21], pitching point absorber [22] or oscillating surge converters [23]).

The fullest and most precise information of the system is imperative for the optimization of the device and maximisation of the generated power, which requires precise mathematical models able to reproduce accurately the behaviour of a device in real sea conditions. Mathematical models are crucial, for example, for power production assessment, simulation of device motions and model-based control strategies.

Wave energy converters (WECs) are, nonetheless, commonly designed and studied by numerical models previously used in offshore engineering industry. Due to the wide range of diverse sea states and conditions that any device operating in the ocean needs to face, different operational modes are used: power production mode, activated within a range of sea-states for which the device is able to produce power without compromising its integrity; and survival mode, activated during extreme sea conditions to avoid structural damage. Similar procedures are also applied in offshore engineering, where nonlinear behaviour is assumed to be important during extreme conditions, but not during power production mode.

However, in contrast to traditional offshore engineering applications, WECs are designed to maximise power absorption with large motion by encouraging the device to oscillate as much as possible- for which control strategies are used. Large motions are therefore usual for wave energy devices, and so nonlinear dynamics may appear not only within the survival mode (which is obvious due to the highly nonlinear behaviour of the device under extreme conditions), but also during power production mode. Accordingly, linear approaches originally created for traditional offshore engineering applications, may not be accurate to reproduce the behaviour of WECs.

Some evidence for different devices, including heaving point absorbers (PAs) [24-26], oscillating pitching converters [27] or oscillating surge converters $[28,29]$ suggest the need of nonlinear models, demonstrating not only the overestimation of linear models in terms of power production, but also the inaccuracy to reproduce the behaviour of WECs over the full range of sea conditions.

Hence, this evidence challenges typical WEC modelling approaches and suggests a scenario divided into three different regions: a linear region, a nonlinear region and a highly nonlinear region, as illustrated in Fig. 1. In such a scenario, nonlinear models would also be essential within the nonlinear region of the power production mode.

Although the vast majority of the models for WECs operating in the power production mode suggested in the literature are linear models, nonlinear approaches are becoming more and more common. The present paper critically analyses the literature, since, to date, no review has been presented, to the best of the authors knowledge, that gives an overall review of the main nonlinear dynamics of different WEC types.

The origin of nonlinear effects has been demonstrated to be very diverse, but three main sources can be identified: the resource or incoming wave (modelling nonlinear incoming waves [30,31]), the device (different nonlinear effects resulting from the wave-device interaction, such as viscous effects [28,27], the variation of the wetted surface due to the motion of the body $[32,24,26]$ or mooring lines $[33,34]$ ) and the power take-off (PTO) system (nonlinear dynamics within the PTO system [21]).

Thus, the present study has two main objectives: Firstly, identifying

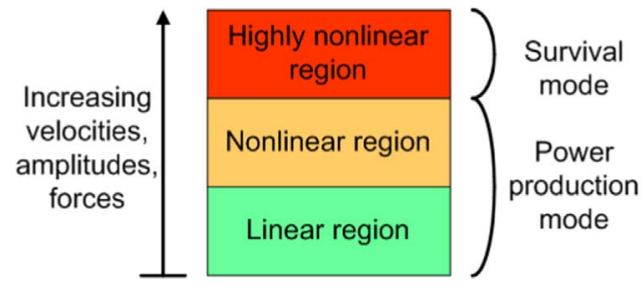

Fig. 1. Different operating regions for wave energy devices. the different nonlinear effects taking part in the wave-device interaction and critically analysing the relevance of such nonlinear effects for different WECs and, secondly, evaluating the different modelling approaches that enable the consideration of such nonlinear effects. Nonlinear physics-based models, such as Navier-Stokes and smooth particle hydrodynamics or different versions of potential flow models (partly-, weakly- and fully-nonlinear methods); and data-based models, determined using system-identification, are reviewed.

Since relevant nonlinear dynamics may vary with the characteristics of each WEC types, the appropriate modelling approach for each WEC type may also vary. Therefore, this paper suggests the most suitable modelling solution for each WEC type in order to efficiently fulfil the requirements of each WEC type. In order to provide a broader perspective of the nonlinear effects present in wave energy converter dynamics, nonlinearities of the incoming wave trains and the PTO systems are, in addition, briefly addressed.

The paper is organised as follows: Section 2 identifies most relevant nonlinear effects and analyses their relevance for each type of WEC, Section 3 evaluates the different existing models to articulate nonlinear effects, and Section 4 presents a critical comparative study of the approaches described in Section 3 and their applicability/suitability for different WECs. Finally, conclusions are drawn in Section 5.

\section{Main nonlinear effects in wave energy converters}

Fig. 2 illustrates the various components and deriving forces for a general WEC. The diagram has been divided into the three main aspects highlighted in Section 1: the resource (the wave) in light blue, the device (and wave-body interaction) in red and the power take-off system in yellow. The three groups (resource, device and PTO) are shortly described in the following subsections.

\subsection{Resource}

Incoming waves, as a direct result of the wind, can be represented in many different ways, from linear monochromatic waves, where waves are basically adjustable (amplitude and frequency) sinusoidal signals to irregular and fully nonlinear (including viscous effects) waves in three dimensions, simulated in a numerical wave tank. Fig. 3 illustrates the appropriate wave theory to be used as a function of the wave height, wave period and the water depth.

Because the present paper focuses on devices operating in the power production mode, only waves that are suitable for power production are considered, avoiding extreme, highly nonlinear, waves. Indeed, it is believed that a large percentage of the wave resource in operational conditions (some researchers suggest over 90\%) can be covered by using linear wave theory. Unfortunately, no reference has been found that addresses the importance of modelling nonlinear waves for wave power production purposes.

Therefore, defining a region of the wave theory diagram under which power can be harvested is useful. However, operational conditions of WECs are highly device-dependent. For each device data from open ocean tests can be used to determine the upper boundary of the power production region in relation to the location characteristics (water depth). Fig. 3 shows such upper boundary of three different devices, the Oyster (near-shore) [36] and the Pelamis (off-shore) WECs [37], deployed at the European Marine Energy Centre (EMEC), and the Sea Power device (off-shore) [38], deployed at the Atlantic Marine Energy Test Site (AMETS), giving a reasonable representation of different WEC types and location characteristics. Hence, an approximate power production mode operation area, the blue area in Fig. 3, is defined.

This power production mode application area suggests that Stokes water waves [40] up to the third order should be considered in intermediate and deep water waves. Stokes' theory, nevertheless, breaks down in shallow water [41], where the alternative can be the 


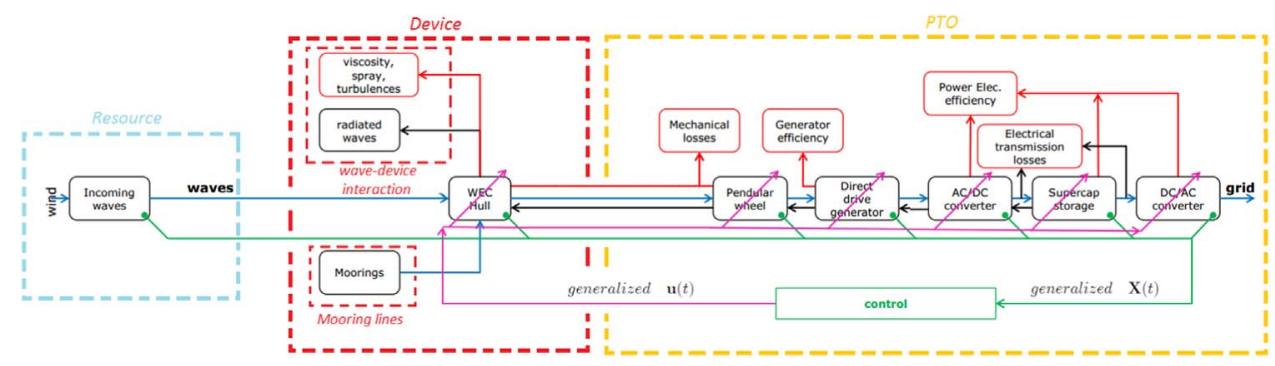

Fig. 2. Block diagram of different aspects participating on the SEAREV device, modified version of the diagram in [35].

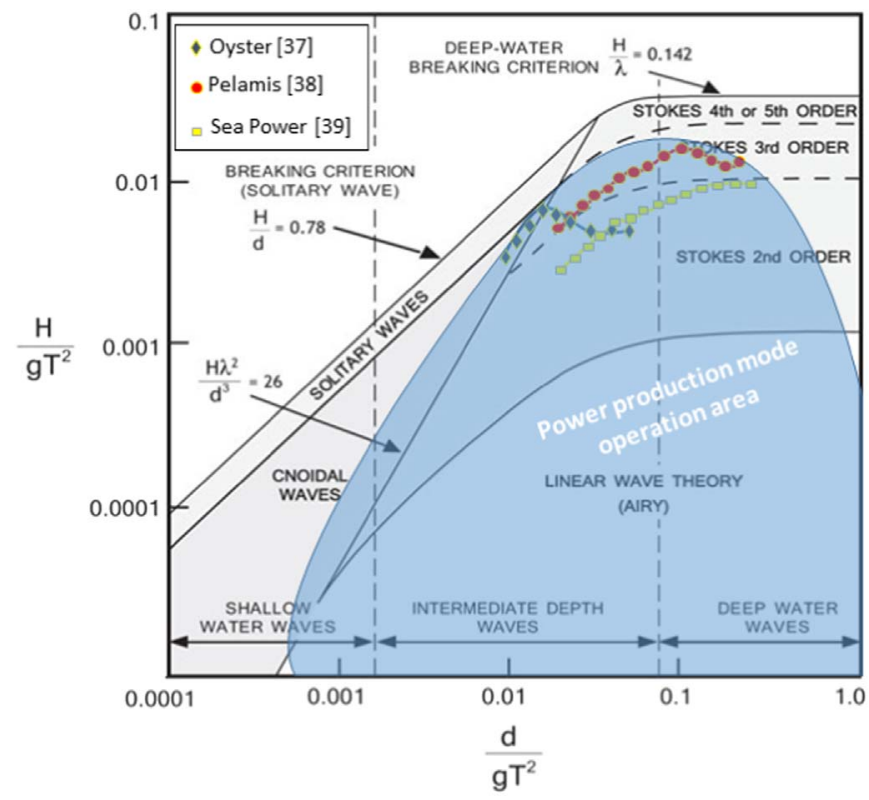

Fig. 3. Wave theory diagram with the application area for power production in wave energy. Figure modified from [39], based on data published in [36] for Aquamarine, in [37] for Pelamis and in [38] for Sea Power.

Cnoidal theory [42], providing waves with sharper crests and flatter troughs.

[41] shows that fifth-order expansion of Stokes' and Cnoidal theories are of acceptable accuracy almost everywhere within the range of validity of each theory, but very high-order expansions are required to get really accurate results. Expansions up to the fifth order largely cover the power production mode application area. Rienecker and Fenton presented an efficient method with simpler equations [43], where equations are solved by Newton's method and coefficients calculated numerically by solving fully nonlinear equations. More details on the different numerical modelling techniques for the propagation of nonlinear waves is given in [44].

In any case, regular (monochromatic) wave theories do not represent real waves, since in the ocean two consecutive waves are never identical. Therefore, irregular wave theories are used to reproduce a real sea-state.

The most established way of describing real sea-states is the Fourier analysis of records taken in different sites. These records are used to create a wave spectrum for real locations, giving the distribution of wave energy among different wave frequency or wave-lengths on the sea surface. Various idealized spectra are used in ocean engineering and oceanography, such as the Pierson-Moskowitz [45], the JONSWAP spectra [46], the Bretschneider [47] or the Ochi-Hubble [48] able to describe a multi-peak spectrum.

Another alternative can be the high order spectral (HOS) method, developed independently in [49] and [50], created to simulate nonlinear free-surface waves [51]. These HOS methods use a spectral expansion and the Fourier transform together with a modified Taylor series expansion to compute the Dirichlet to Neumann map on the freesurface.

While Fourier analysis and spectral methods are well established, other methods may provide more insight into the wave physics, especially in non-stationary and highly non-linear conditions. [52] presents a method, for which the key part is the empirical mode decomposition (EMD), allowing the decomposition of any data set, no matter how complicated, into a finite and small number of intrinsic mode functions that admit Hilbert transforms. The main advantage is the definition of an instantaneous frequency, varying in time, which retains physical meaning in a more compact decomposition using different time scales.

Fully nonlinear, non-breaking, three dimensional waves can also be implemented in a numerical wave tank. [53,54] present a method based on a fast iterative algorithm to compute the Dirichlet to Neumann operator and is able to create fully nonlinear waves.

\subsection{Device}

In order to analyse nonlinear effects of the device, time domain models are required. Eq. (1) represents all the forces acting on a wave energy device, without specifying the way they interact

$$
\begin{gathered}
M \ddot{X}(t)=f\left(F_{g}, F_{F K}(t), F_{\text {diff }}(t), F_{\text {rad }}(t),\right. \\
\left.F_{\text {vis }}(t), F_{P T O}(t), F_{\text {moor }}(t), F_{\text {add }}(t)\right)
\end{gathered}
$$

where $F_{g}$ is the gravity force, $F_{F K}$ the Froude-Krylov force, $F_{d i f f}$ the diffraction force, $F_{\text {rad }}$ the radiation force, $F_{v i s}$ the viscous force, $F_{P T O}$ the force acting on the structure due to the power take off (PTO) system, $F_{\text {moor }}$ the force due to the mooring lines and $F_{\text {add }}$ the force corresponding to any other additional force, such as drift, wind, tidal or other body-water interactions.

The following subsections analyse the different forces acting on the device, those presented in Eq. (1) except $F_{\text {add }}$, and the nonlinear dynamics resulting from the wave-device interaction.

\subsubsection{Froude-Krylov force}

The Froude-Krylov (FK) force is the load introduced by the unsteady pressure field generated by undisturbed waves. It is generally divided into static $\left(F_{F K_{\text {stat }}}\right)$ and dynamic $\left(F_{F K_{d y n}}\right)$ forces. The static part represents the relation between gravity and buoyancy forces in a static situation with a still ocean, while the dynamic part represents the force of the incident wave.

Linear codes compute the FK force over the mean surface of the body, while nonlinear computation requires the integration of the incident wave pressure and the hydrostatic force over the instantaneous wetted surface at each time step. Different techniques to compute nonlinear FK forces are presented in Section 3.2.2.

The linear representation of FK forces loses accuracy when analysing large relative motions between the free-surface elevation and the device motion, when wetted surface varies considerably over time.

\subsubsection{Diffraction and radiation forces}

The diffraction force is the load associated with the action of the 
diffracted wave. This disturbance is introduced into the wave system by the presence of the floating bodies. FK forces, together with diffraction force, make up the total non-viscous hydrodynamic forces acting on a floating body.

[55] mentions that neglecting the diffraction term might be a reasonable approximation to the excitation force if the body is very small in comparison to the wavelength. In addition, it is computationally convenient to use this approximation.

The radiation force, on the other hand, is the hydrodynamic force associated with the motion of the floating body, also expressed by a convolution product according to Cummins equation [56].

In general, a linear approach for the radiation force is reasonably good for devices which are much smaller than the wavelength, as in the case of diffraction force [31,32]. However, a more precise computation of diffraction-radiation time-derivative terms is possible, as shown in Section 3.2.2.

\subsubsection{Viscous force}

In the traditional offshore industry, in which hydrodynamic models have been mainly based on linear potential flow theory, viscous losses are considered relevant for structures that are small compared to the wave amplitude. Since offshore structures are, in general, relatively large (offshore oil and gas platforms or ships), viscous losses are minor losses, except for localized effects, such as vortex shedding generation in sharp edges.

Wave energy devices are generally small devices, especially pointabsorbers, and so viscous effects, at least in theory, can be relevant.

\subsubsection{Parametrically excited motions}

Any object floating in the ocean, e.g. ships or WECs, may experience the parametric amplification of roll/pitch motions caused by the nonlinear coupling of at least two degrees of freedom. This coupling appears when the incident wave has a frequency of approximately twice the resonance roll/pitch frequency. This nonlinear effect is also known in the literature as Mathieu-type instability [57], and has been investigated since the $60 \mathrm{~s}$ in the offshore and shipping industries [58].

The instability is related to the geometrical characteristics of the floating object, caused by the dynamic variation of the metacentre position as a consequence of the heave motion. Basically, the metacentre height becomes negative at some points during the simulation/ experiment, which makes the object unstable, causing large roll/pitch motion amplitudes.

The phenomenon of parametrically excited motions has also been identified in wave energy converters when testing devices in real wave tanks $[27,59,60]$. Since, it is related to a loss of hydrostatic stability in situations of large displacements, nonlinear potential models, such those presented in Section 3.2.2, should be able to predict the phenomenon.

\subsubsection{Sloshing}

When a liquid is enclosed in a container and the liquid has a freesurface within that container, slosh dynamics refer to the movement of the liquid in the container, which can severely affect the system dynamics [61]. The sloshing phenomenon has been very much studied in ships and trucks transporting liquids and is highly nonlinear. Hence, sloshing must be studied using fully nonlinear methods that include viscosity effects, described in Section 3.1.

Sloshing effect can only appear in very specific WECs, where sea water can be considered to be enclosed. Hence, the sloshing effect is effectively restricted to oscillating water column devices [62] or specific concepts with an internal fluid tank $[63,64]$.

\subsubsection{Slamming}

Slamming is the impact of an object in the ocean onto the free surface, which is very typical in some wave energy devices when the device raises from the free surface and subsequently impacts it. Impact events are very typical under extreme conditions, which are out of the scope of this paper, but also appear when operating in the power production mode, especially in devices where energy is extracted by means of a rotation motion. Slamming is a highly nonlinear phenomenon that requires wave tank experiments or fully nonlinear modelling methods. The key variables of a slamming event are the pressure magnitude, the duration of the event and the spatial distribution [65].

\subsubsection{Mooring system force}

WECs are subject to drift forces due to waves, currents and wind, and so they have to be kept on station by moorings. The offshore industry uses many different configurations, for different offshore applications. [66] studies mooring requirements for wave energy converters, listing some of the most important requirements, and the suitability of existing mooring configurations for wave energy devices.

Nonlinear effects in mooring lines seem, in general, to be much more significant in the case of slack moorings than in the case of tightly moored devices [34].

[67] presents a first approach for slack mooring lines, where cables are modelled as catenary lines by means of a quasi-static representation, where the nonlinear behaviour of a mooring line is clearly demonstrated for surge motion. Similar approaches are used in [33], for the slack mooring system, and in [34], for the tightly moored systems, to articulate nonlinear mooring forces.

However, quasi-static approximations cannot cover important dynamic effects, such as cable inertia, viscous drag forces or effects due to the slowly varying forces. [68] presents some measurements where the relevance of the dynamic effects is demonstrated by comparing experimental results with two different simulations: a simulation run with the fully-dynamic software OrcaFlex [69] and a quasi-static simulation presented in [70].

\subsubsection{Relevance of nonlinear effects}

The very diverse WEC concepts based on very diverse working principals make the idea of a general mathematical model extremely difficult. Therefore, it is useful to gather all the diverse concepts in few different groups, in order to identify the main nonlinear effects of each group.

In terms of WEC classification, different studies have analysed the state of the art of wave energy devices, where the vast majority of the existing devices or technologies are organised via between three and five groups. Some studies [71,72] suggest a classification with three different groups (oscillation water column (OWC), oscillating bodies and overtopping converters), while [73] proposes five groups (attenuators, point absorbers, oscillating wave surge converters, OWC and submerged pressure differential).

Based on the aforementioned classifications, the present paper divides the main devices (those which reached the prototype stage or have been sufficiently developed to be considered as feasible in practice) into four groups according to their working principles and motion characteristics, with special attention paid to the relevance of different nonlinear effects:

- Oscillating water column converter (OWC)

- Heaving Point-Absorber (HPA)

- Oscillating Pitching Converter (OPC)

- Oscillating Surge Converter (OSC)

Examples of each WEC group are given in Table 2. Overtopping devices, which form a group in all the aforementioned classifications, are omitted in this paper, because overtopping itself is an extremely nonlinear phenomenon and essential effects, such as green water or breaking waves, can only be analysed by using fully nonlinear codes.

The most important nonlinear effects of each WEC group are analysed in the following subsections. 

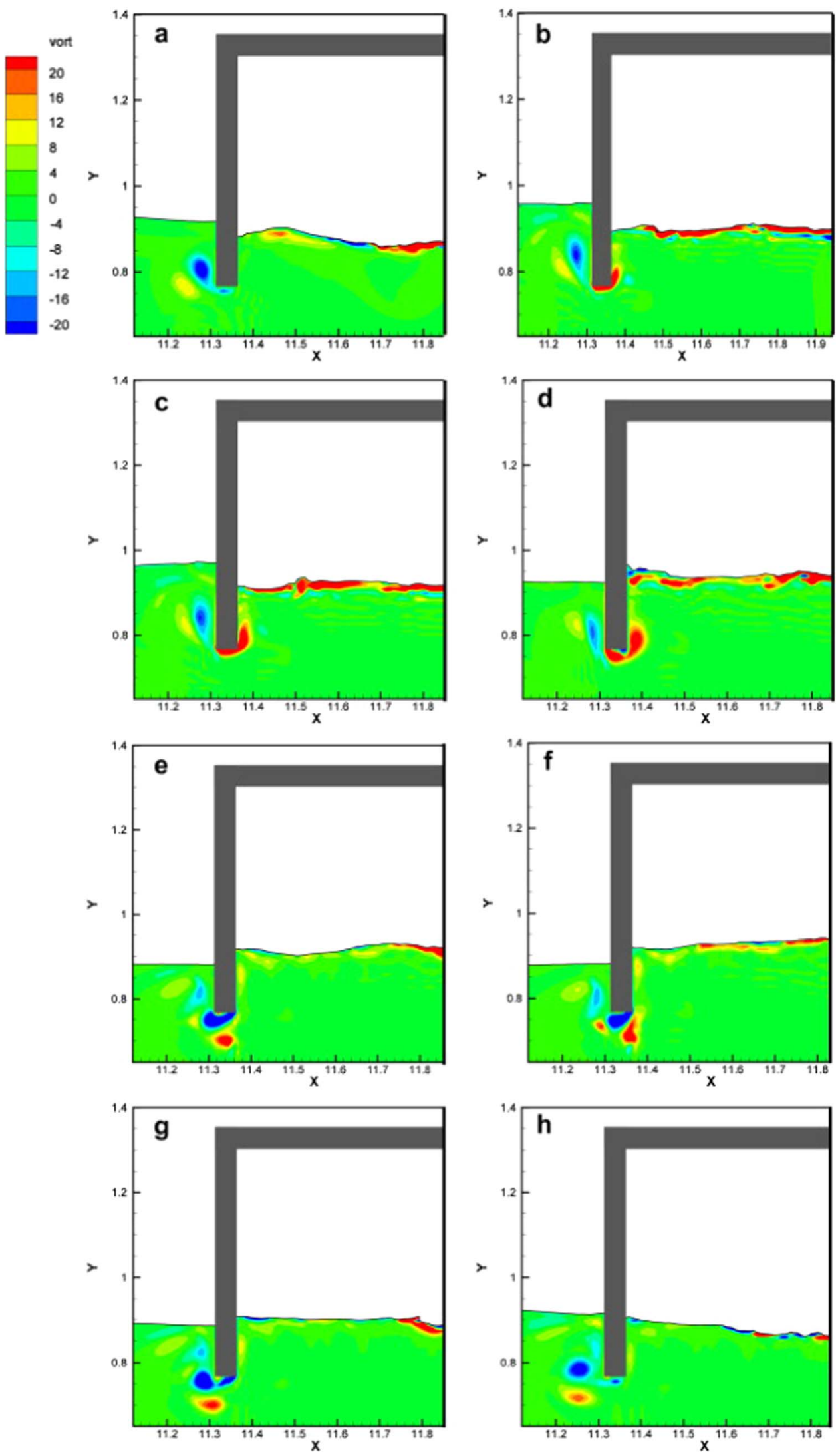

Fig. 4. The cycle of the water-column behaviour within one wave period, [62].

2.2.8.1. Oscillating water column converter. Nonlinear FK forces are an important factor, as the variation of the entrained water mass in the chamber depends on the relative motion between the device structure and the free-surface, and so the pressure of the water mass inside the chamber and the absorbed power can be more accurately computed [74]. In addition, and related to nonlinear FK forces, parametrically 
excited motions can appear in floating OWCs, as shown in [59], causing large motion amplitudes in pitch and roll. The Mathieu-type instability turns the desirable heave motion into an inconvenient pitch or roll motion, negatively impacting the energy harvesting.

Viscous effects important in OWCs. In onshore located fixed OWCs, where waves have normally already broken, waves arrive at the chamber with high components of turbulence and generate shedding vortices around the outer wall of the chamber. A similar phenomenon appears in the case of floating devices, although waves are not broken in that case. [62] demonstrates this phenomenon by simulating the fluid around and inside a fixed OWC converter, covering the whole cycle of vortex generation and free surface elevation, as illustrated in Fig. 4.

The behaviour of the free surface inside the chamber during the cycle is highly nonlinear. Hence, the free-surface elevation modelled by linear approaches such as the piston model used in commercial codes such as WAMIT [75], AQWA [76] or Aquaplus [77], may under- or over-estimate the pressure differential in the chamber [78,79].

Furthermore, especially in the case of a floating oscillating water column where a partially empty tank is moving, a sloshing effect may appear, resulting in significant variations of the fluid behaviour inside the chamber [80]. Dynamic forces caused by liquid sloshing cannot currently be captured by seakeeping software, and therefore, fully nonlinear modelling approaches become necessary [81]. The sloshing phenomena in floating structures creates a non-uniform force field in the chamber, with direct consequences on the whole body dynamics and stability, as seen in [82].

Viscous effects can be analysed by models that already incorporate viscous effects automatically, as in [83], or by including them externally through a calibration process by using experimental data or fully viscous simulations, as in [84].

2.2.8.2. Heaving point absorber. Linear computation of FroudeKrylov forces can be accurate for small motions, or even for situations where the device behaves as a wave follower, but lose accuracy when the relative motion between the device and the freesurface increases. Although considering only the nonlinear restoring force, static Froude-Krylov force, appears acceptable in some cases [85], when the relative motion between the device and the free-surface is large enough, for example, when the device resonates due to a control strategy, the influence of the nonlinear Froude-Krylov on the dynamics of the system becomes important [26]. Indeed, the nonlinear implementation of restoring force alone can lead to unbalanced models that provide even lower accuracy than linear models [86]. In such situations, linear models tend to overestimate the motion of the device and, as a consequence, the power absorption. Furthermore, control strategies based on linear models lose performance [26].

There is, however, a geometric factor to be considered, as pointed out in [26] and more clearly in [30]. Nonlinear Froude-Krylov effects can be important, even for small and flat waves, in the case where the crosssectional area is non-uniform, such as a sphere, while the linear model representation appears to be reasonable for the case where the crosssection is uniform. Fig. 5 illustrates the power overestimation of the models with linear FK forces; the loss of performance of control strategies based on linear models; and the geometrical factor of FK forces.

Parametrically excited motions must be considered in HPAs with more than one degree of freedom. Self-reacting devices, where coupling between different modes is important, are highly sensitive to the nonlinear coupling of heave, roll or pitch. [60] clearly demonstrates that the nonlinear heave, roll and pitch coupling occurs at large motion amplitudes and that the partially linear potential model is able to predict the parametric resonance, validating the model against experimental tests in a wave tank.
Viscous effects appear to have a low influence in small heaving point absorbers $[87,85]$. Vortex shedding is generated by the motion of the body relative to the surrounding fluid, but this shedding is not powerful enough to produce considerable changes in the behaviour of the body and its power production capacity.

[88] studies the nonlinear hydrodynamic force relevance for HPAs and OSCs, where clearly states that FK force, and more specifically dynamic FK force, is the main force in HPAs, while the impact of the viscous effect is low, as shown in Fig. 7 (a) and Table 1.

However, some two-body HPAs use a damping plate attached to the bottom of the central floater, which enhances the vortex shedding process changing the hydrodynamic properties by introducing extra damping (viscous damping) and increasing the added-mass [89]. Same strategy has been used in different offshore oil and gas platforms. If a damping plate is included, the extra viscous damping should not be neglected [90].

Oscillating pitching converters [27] has proven nonlinear hydrodynamic behaviour in wave tank experiments, such as parametric roll or slamming phenomena, illustrated in Fig. 6 (a) and (b) respectively, which could never be predicted by linear numerical models.

In the same way as HPAs, the computation of nonlinear FK forces is crucial for OPCs in order to predict the parametrically excited modes [27]. In addition, fast and large motions, typical in OPCs, encourage the formation of vortex shedding and other viscous effects. Therefore, viscous effects become important and lead to highly nonlinear effects like the slamming events that dissipate energy and limit the amplitude of the motions, as shown in Fig. 6 (b).

Such nonlinear behaviour can only be predicted by fully nonlinear models including viscosity effects. Indeed, the viscous model needs to be suitably adapted to capture such behaviours.

2.2.8.3. Oscillating surge converters. Following [88], radiation and diffraction forces and viscous drag force are prevailing, as illustrated in Fig. 7 (b). The fact that radiation and diffraction are dominating in OSCs suggests that the impact of nonlinear radiation and diffraction may not be negligible, as it happens with OWCs, HPAs or OPCs. Unfortunately, no study was found in the literature that confirms or refuses the relevance of nonlinear radiation/diffraction forces in OSCs.

Different studies have analysed viscous effects of the surging devices and important nonlinear behaviour, such as the slamming phenomenon, has been observed. Turbulent vortices around surging converters are normally strong and have a significant impact on the motion [28], as shown in Table 1.

Slamming characteristics have been studied in [91,92] demonstrating the need to satisfactorily capture the slamming phenomenon in OSCs to accurately predict the behaviour of the device. Slamming events in WECs are still barely explored events and so more investigations are required to fully understand, for example, the cause of the sudden plunge of the water level in front of the device prior to the impact. In addition, due to the slamming phenomenon, a water jet is created as the device re-enters the water [93]. This water jet travels up the face of the flap and is finally ejected when the flap enters the water.

Table 2 presents a comparative study of the impact of nonlinear effects on different WEC types. The relevance of the FK, radiation/ diffraction and viscous forces is evaluated for each WEC type, providing the literature references in each case. In addition, particular nonlinear effects that are important to consider in each WEC-type are given.

\subsection{Power take-off force}

Different PTO systems are under development for wave energy devices, such as turbine transfer PTO (with air or sea-water as the working fluid), high-pressure hydraulic systems or direct drives [99]. With the exception of direct drives, all PTO systems convert the energy of the waves into electric power in two stages. 


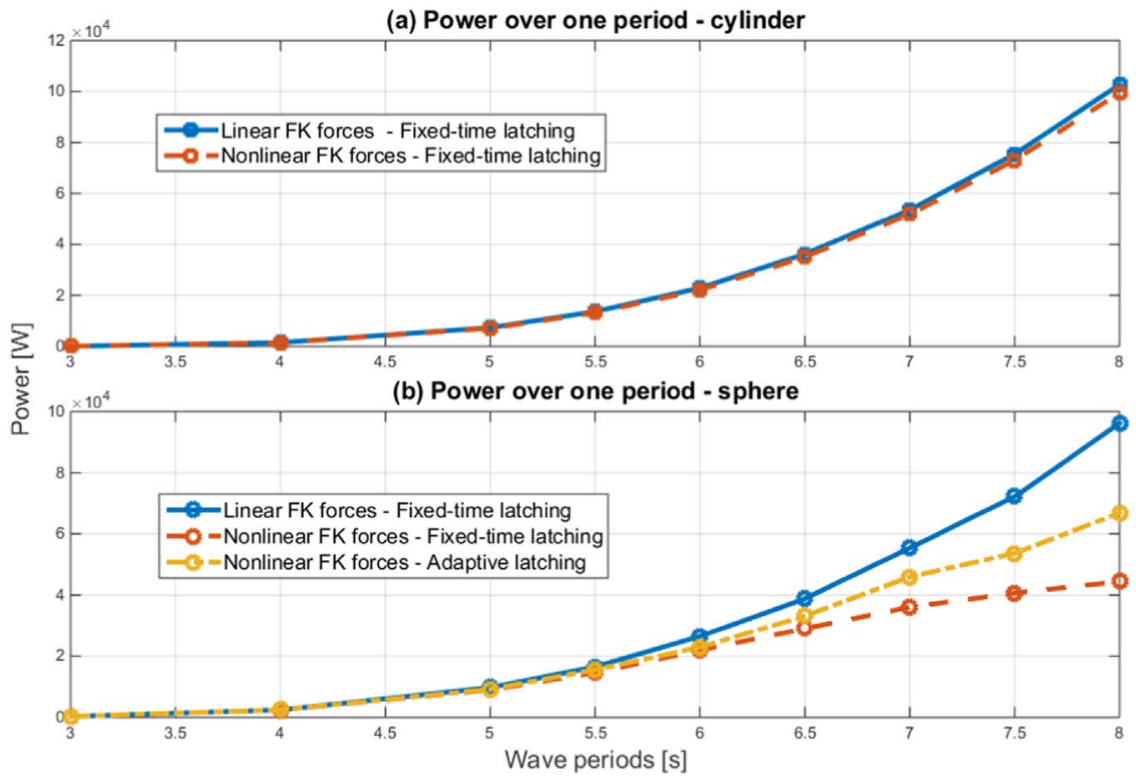

Fig. 5. Power absorption for a cylinder and a sphere with linear and nonlinear computation of FK forces with latching control strategy, [30].

Table 1

Viscous effects and their relevance for HPAs and OSCs, in terms of absorbed power production (APP), from [87] and [28].

\begin{tabular}{llll}
\hline $\begin{array}{l}\text { WEC } \\
\text { type }\end{array}$ & $\begin{array}{l}\text { Energy } \\
\text { output }\end{array}$ & $\begin{array}{l}\text { Without } \\
\text { viscous term }\end{array}$ & $\begin{array}{l}\text { With } \\
\text { viscous term }\end{array}$ \\
\hline $\begin{array}{l}\text { Heaving PA } \\
\text { Surging converter }\end{array}$ & AEP & $58 \mathrm{~kW}$ & $56 \mathrm{~kW}$ \\
& APP & $114 \mathrm{~kW}$ & $74.4 \mathrm{~kW}$ \\
\hline
\end{tabular}

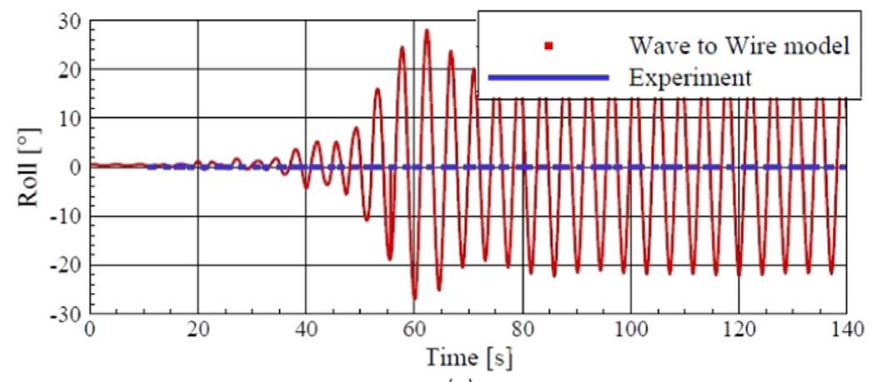

(a)

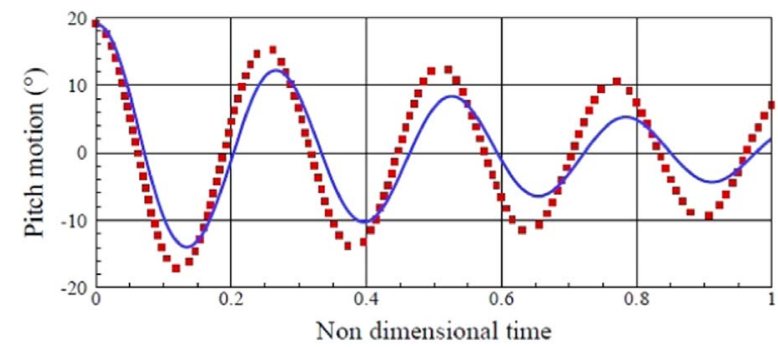

(b)

Fig. 6. Nonlinear behaviour of the SEAREV device at large motions: (a) parametric roll and (b) motion reduction due to slamming, modified from [27].

In many studies, PTO systems are modelled as a linear spring and damper in parallel, or even just as a single linear damper, consciously avoiding nonlinear effects, which does not mean the relevance of nonlinear effects in PTO systems is low. [100] studies all the different aspects from the wave to the grid, where all kind of PTO systems and their characteristics are analysed, including losses and efficiencies.

Different sources of the nonlinearities for each type of PTO system are identified in Sections 2.3.1, 2.3.2 and 2.3.3.

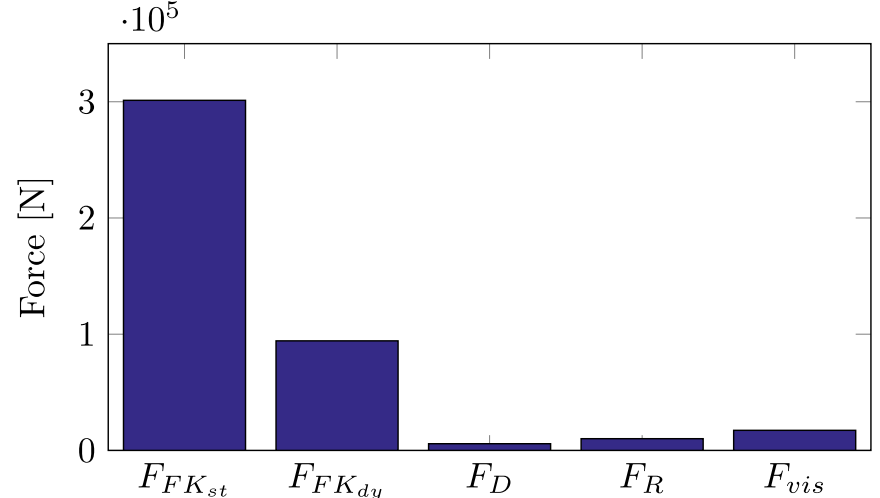

(a) Heaving point absorber.

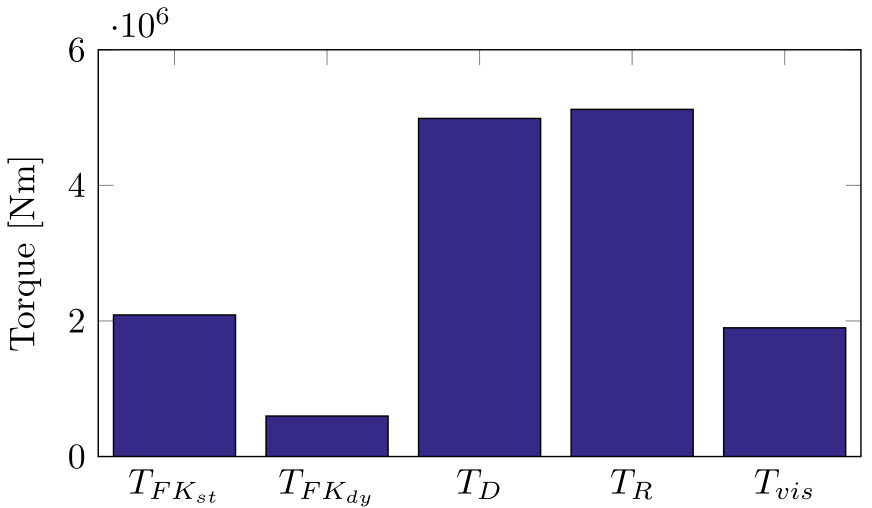

(b) Oscillating surge converter.

Fig. 7. Total hydrodynamic force $(F)$ and torque $(T)$ decomposition into static FK $\left(F K_{\text {st }}\right)$, dynamic FK $\left(F K_{d y}\right)$, diffraction $(D)$, radiation $(R)$ and viscous drag (vis) under controlled conditions, using a regular wave of period $T_{w} 10 \mathrm{~s}$ and height $H_{w} 1 \mathrm{~m}$, [88].

\subsubsection{Air-turbines}

Different turbines for OWC converters are under development [101], including the Wells turbine [102] which is 'clearly the most frequently proposed and/or used air turbine to equip OWC plants' [71].

Among the different options to model the different air turbines in the literature, the turbine induced damping studied in [103,104] suggests a linear relationship between chamber pressure and air mass 
flow for Wells turbines and a nonlinear relation for self-rectifying impulse turbines. [105] reaches the same conclusion comparing experimental tests and numerical models (using a fully nonlinear RANS-VOF model) for regular and irregular waves.

Main nonlinear effects in air turbines are the air compressibility in the chamber and the losses, which should be carefully included in order to get accurate results.

\subsubsection{High-pressure hydraulics}

High-pressure hydraulic systems are highly nonlinear systems, particularly suitable for slow motions, either in translation or rotation, linked to large forces or moments. A high-pressure hydraulic system consists of a hydraulic cylinder, valves, accumulators, a hydraulic motor and hoses to connect the different components.

In order to consider different nonlinear effects in different components of the hydraulic circuit, the model should at least consider friction and fluid inertia forces and fluid compressibility in the cylinder [106], pressure loses in the hoses [107,108]; time-varying gas volume and pressure in the accumulators (including compressibility of the fluid) [109]; and compressibility and friction losses on the motor and the valves (leakages) [109,110].

\subsubsection{Direct drive}

A direct drive linear generator generally consists of three parts: the armature, the translator and a set of springs attached between the seabed and the armature. [111] describes different available concepts, such as the linear permanent magnet synchronous machine, the linear air-cored permanent magnet synchronous machine, the slot-less tubular permanent magnet synchronous machine or the Snapper concept, which has been specifically developed for wave energy conversion purposes under the seventh framework programme funded by the European Community [112].

$[113,114]$ describe different forces, some of which can lead to nonlinear behaviour, that are involved in the operation within the machine: the interaction of the two sets of magnets, electromagnetic damping due to the current carrying coils and other forces due to different losses such as eddy currents in armature and translator, saturation and reactive field losses, and losses due to proximity effects.

\section{Nonlinear modelling approaches}

A critical classification of the existing modelling approaches for wave-device hydrodynamic interaction is presented in this section. This classification is organised following, first of all, the physical theory the models are based on and, secondly, the way in which nonlinear effects are treated. Hence, the main existing models are divided into three groups (Navier-Stokes and smoothed-particle hydrodynamics, potential flow models and models from data).

When studying nonlinear effects, diverse strategies are adopted; some authors use fully nonlinear methods [115,116,87,27], which include any nonlinear effect of the incoming wave and water-body interaction. Other studies adopt partially nonlinear methods, where, in general, potential flow methods are used including nonlinear effects, either by extending the linear model $[31,26]$ or by inserting in the Cummins equation as an external load $[21,117]$.

Another alternative suggested in the literature is that of data-based models determined using system-identification, referred to as models from data in the present paper, where models are determined from input/output data. In spite of being relatively new and unexploited modelling wave energy converters, their success in other fields, such as control applications, suggests they can be a useful modelling option.

\subsection{CFD and SPH models}

CFD and SPH models are both fully nonlinear models,for which the main difference between the two options is the domain discretization 
method: mesh-based in CFD and mesh free in SPH (uses an array of particles to form the domain).

The behaviour of a fluid is analysed by solving a set of differential equations known as the Navier-Stokes equations. The fundamental basis of almost all problems are governed by the transfer of mass, momentum and heat, described by the following equations: the continuity Eq. (2), the equation of motion (3) and conservation of energy (4):

$\frac{\partial \rho}{\partial t}+\nabla(\rho u)=0$

$\frac{\partial u}{\partial t}+(u \nabla) u=-\frac{1}{\rho} \nabla p+F+\frac{\mu}{\rho} \nabla^{2} u$

$\rho\left(\frac{\partial \epsilon}{\partial t}+u \nabla \epsilon\right)-\nabla\left(K_{H} \nabla T\right)+\rho \nabla u=0$

where $\rho$ is the fluid density, $u$ the velocity vector, $p$ the pressure field, $F$ the external force per unit mass, $\mu$ the fluid viscosity, $\epsilon$ the internal energy, $K_{H}$ the heat conduction coefficient, and $T$ the temperature.

However, Eqs. (2)-(4) cannot be solved analytically, and so numerical discretization is necessary to obtain a solution. It is at this point where computational codes are employed implementing complete Navier-Stokes equations. The phenomenon to be simulated, the computation capacity of our machine and/or the fidelity requirement drive the decision between the different approaches.

In the case of wave energy, wave tank experiments or real-sea tests can be implemented in numerical wave tanks [118]. These simulations have been used for decades in offshore and ocean engineering for fluidbody interaction analysis.

\subsubsection{Computational fluid dynamics}

CFD numerically solves the Navier-Stokes equations by numerically discretizing space and time. The main issue when modelling WECs using CFD is the presence of a free-surface. Specific free-surface modelling techniques have been developed, which can be classified into two main categories [119]: fitting methods (also known as tracking methods) [120] and capturing methods [121]. The tracking method models the free surface as a sharp boundary [122], while the interfacecapturing method includes water and air in the mesh, adopting either the volume of fluid (VOF) method [123] or the level-set formulation [124]. Free surface capturing methods are more common in hydrodynamic applications [125], mainly because they are more robust, since remeshing is not required. Further details on numerical CFD discretization methods are given in [126].

In wave energy, especially in real devices, the flow is considered turbulent, which suggests the use of the Reynolds decomposition of the fluid velocity. The Reynolds decomposition consists of decomposing instantaneous quantities into time-averaged and fluctuating quantities. Therefore, Navier-Stokes equations become Reynolds-Average NavierStokes (RANS) equations, giving approximate time-averaged solutions to the Navier-Stokes equations. RANS is the most widely used method, due to the high computational requirements of other methods like the large eddy simulation (LES) or the direct numerical simulation (DNS).

In order to produce a closed system of solvable equations, RANS equations require a turbulence model. [127] presents a classification of different turbulence models, where the two most common models are the two-equation $k-\epsilon$ model $[128,129]$ and the $k-\omega$ model [129], where $\mathrm{k}$ refers to the turbulent kinetic energy in both models and the second term refers to the dissipation of the turbulence kinetic energy $(\epsilon)$ or the turbulence frequency $(\omega)$. The $\mathrm{k}-\epsilon$ model is more robust and computationally cheaper, but performs poorly under severe pressure gradients, while the $k-\omega$ model shows superior performance under adverse pressure gradients and separation, although separation is typically exaggerated and predicted too early. Shear stress transport (SST) turbulence models have also been suggested, using $k-\epsilon$ away from walls and the $k-\omega$ near walls $[130,131]$. Although the SST model is stated to be more appropriate for separated flows giving highly accurate predictions of the onset and the amount of flow separation under adverse pressure gradients $[132,130]$ concludes there is a week dependency to changes in turbulence model. A comparative study of the different turbulence models can be found in [133].

NWT simulations implemented in CFD codes have some advantages and drawbacks when compared to real wave tank tests, but both appear to be essential in the process towards an optimal WEC design. NWT simulations avoid, on the one hand, the complexity and costs of building a real prototype and on the other, the scale effects [134], as full scale devices can be numerically simulated. In addition, reflection effects from tank walls can be controlled effectively and a large variety of situations can be implemented with different incident waves or forces applied to the device.

[135] presents the main advantages and drawbacks of using CFD methods in the design process of a WEC, with the main weakness being the high computational requirement.

\subsubsection{Hydrodynamic modelling approaches for wave energy}

In general, CFD codes are very general codes used for many and varied applications where fluid-flows are considered. Nevertheless, other models specifically created for analysing wave-structure interactions are also available. This paper describes two of these specific models: the Spectral Wave Explicit Navier-Stokes Equation (SWENSE), developed by the Hydrodynamic and Ocean Engineering group of the Ecole Centrale de Nantes (ECN) [136] and the IH2VOF developed at IH Cantabria [137].

3.1.2.1. SWENSE. The SWENSE approach based on RANS equations combines the advantages of potential and viscous solvers, by solving each physical problem with the appropriate tool: the propagation of the waves with the potential flow solver and the diffraction-radiation problem with the viscous solver [138]. Hence, the simulation is divided into two different steps, where undisturbed incident waves are analysed by a nonlinear spectral scheme based on potential flow theory, while the computation of the nonlinear viscous flow uses the free surface RANS solver ICARE $[139,140]$, which adopts the tracking method to model the free surface. The coupling of the potential and viscous solvers is implemented by incorporating incident flow parameters as forcing terms into the modified RANS equations.

3.1.2.2. IH2VOF. The IH2VOF model was initially created for coastal structures and includes realistic second order wave generation and active wave absorption. It solves the 2-D wave flow by the resolution of the volume-averaged Reynolds-averaged Navier-Stokes (VARANS) equations, based on the decomposition of the instantaneous velocity and pressure fields and the $k-\epsilon$ equations [141].

Both the SWENSE and the IH2VOF models have been already validated during their development period. The SWENSE code has confirmed its accuracy and CPU requirement savings for the DTMB5415 model [142] and TLP structures [143]. The IH2VOF model, on the other hand, has been validated for coastal structures [144], wave breaking slopes [145] and breakwaters [146].

\subsubsection{Smooth-particles hydrodynamics}

The SPH method is a purely Lagrangian meshless interpolation method that can approximate continuously field quantities and their derivatives by using discrete sample points, called smoothed particles. These discrete elements or particles are transported with the local velocity and they carry the information of the field, such as mass, pressure or density.

Different SPH techniques may be implemented, as shown in [147], 
depending on the characteristics of the flow and the problem to be studied. SPH was originally developed for astrophysics [148], but has been applied to diverse applications [149,150], including marine environment hydrodynamic problems [151] and, more specifically, hydrodynamic interactions in the presence of a free-surface [152]. The interpolation of the smoothing kernel outside the boundary may lead to inconsistent behaviour of the system [153], and so may require special treatment. Other alternative particle methods, such as the movingparticle semi-implicit method [154] or the consistent particle method [155], have also been suggested in the literature, but have never been implemented in a wave energy problem, to the best knowledge of the authors. In the case of moving-particle semi-implicit method, additional mass-density and pressure correction terms are used, which must be solved simultaneously, complicating the problem.

Thus, the fields are just defined at these discrete points. In order to define continuous fields, smoothing kernel functions (or weighting functions) are used, which specify the contribution of a typical field variables at any position. This means for example, that pressure at any position $(r)$ depends on the pressure of all the particles within a radial distance $h$, also known as smoothing length.

The contribution of all the particles within this radial distance to a property of the particle being analysed is not the same. This contribution is weighted relative to the distance between the analysed particle and the contributor particle $\left(r-r_{j}\right)$ and their density. This is mathematically governed by the kernel function, illustrated in Fig. 8. As a consequence, the field variable is known at a discrete set of points $(N)$ within this radial distance and can be defined as follows:

$A(r)=\sum_{j}^{N} \frac{m_{j}}{\rho_{j}} A\left(r_{j}\right) W\left(r-r_{j}, h\right)$

where $A(r)$ could be any field variable at any position $r, N$ is the number of particles, $m$ the mass and $\rho$ the density associated with the particle, and $W$ is the kernel function.

The choice of the smoothing kernel function for a specific problem is essential, with the Gaussian kernel being a good initial option [157]. Despite the beneficial mathematical properties of the Gaussian kernel, it does not have compact support, which is required in to solve the interparticle computations. [158] studies different options for the smoothing kernel in stable field, and suggests the q-spline kernel as the best choice. The same kernel function is used in [151] for freesurface hydrodynamic problems; however, the q-spline kernel may be computationally expensive if the kernel needs to be recomputed frequently. Other functions, such as the 6th order polynomial kernel [159] or the quintic Wendland kernel [160] have also been suggested in the literature as more efficient alternatives. Indeed, with regard to wave energy applications, the quintic Wendland kernel is the most commonly implemented kernel $[161,65,162,163]$, probably because it was found to give the best compromise between accuracy and computation [164].

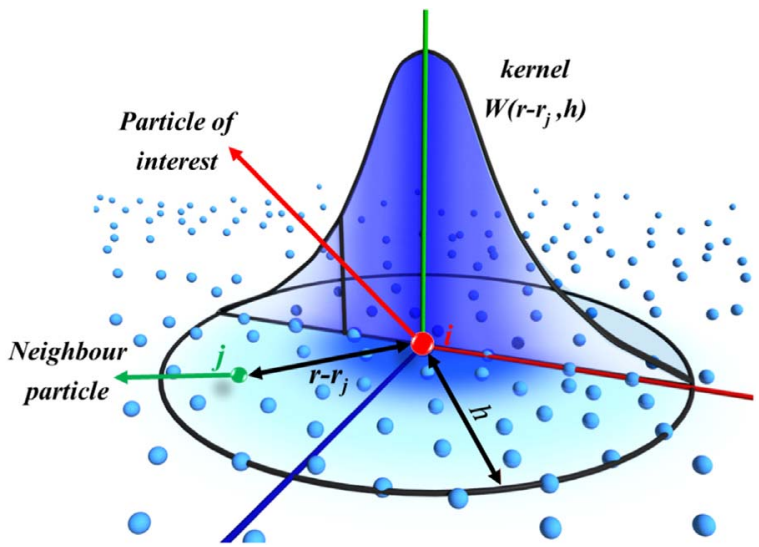

Fig. 8. The principle of the SPH kernel function, modified from [156].
The smoothing length of a particle is also of significant importance and can be fixed in space and in time. However, it is also possible to assign a smoothing length to each particle and make it vary in time. That way, the resolution of the simulation will be adapted automatically depending on the local conditions of the area, where this particle is located in that precise moment. The automatic adaptation of the resolution optimizes the computational cost of the simulation by optimizing the requirements of each region of the simulation.

This adaptability is comparable to the adaptive mesh refinement (AMR) codes in grid-based methods. In AMR methods, the grid is adapted dynamically to give more accurate results in determined uncertain regions. Lagrangian-adaptability is even simpler, due to the absence of explicit topology in the SPH particles. This adaptability in SPH can be introduced via two different methods: changing a particle's smoothing length or dividing the particle into 'daughter' particles, with smaller smoothing lengths. In hydrodynamic studies, the method using 'daughter' particles is the most widely used. The conditions used to split particles into smaller 'daughter' particles, e.g. proximity to the free-surface, can be defined in the model.

In a SPH simulation with a free-surface, the fluid consists of a constant number of particles with a constant mass (particle mass is a user defined parameter), implying that mass conservation is guaranteed. Hence, the total force acting on each particle is specified, which can be divided into internal (pressure or viscosity) and external forces (gravity or buoyancy). External forces can arise from the presence of a wave energy device, a rigid floating body in the vast majority of the cases, which can be included in the SPH model as a set of extra particles [151]. The particles that form the WEC are similar to the particles that form the boundary walls. The individual forces on the different particles of the floating body are summed to represent a total force and moment at the centre of gravity of the body.

In SPH, two main approaches are available to calculate pressure: the weekly compressible SPH (WCSPH) and the incompressible SPH (ISPH). The ISPH is suggested as an improved alternative [165] to the WCSPH, providing improved accuracy with larger time steps and reducing the pressure noise. However, the use of the time-consuming Poisson's equation to compute the pressure at each time step significantly increases the computation time; each time step can be computed up to twenty times faster in a WCSPH model, compared to a ISPH model [166]. With regard to wave energy applications, the WCSPH method has been typically used [161,65,167-169], although the ISPH method has also been implemented $[162,163]$ in order to reduce the pressure oscillations (pressure noise) typical of WCSPH.

Most of the studies using SPH in wave energy applications are focused on extreme events $[65,169,162,163]$, where the SPH can have significantly greater fidelity than CFD. However, such extreme events are beyond the scope of this paper. When SPH has been implemented to study WECs' behaviour under operational conditions, results showed good agreement with experimental results.

[161] uses the WCSPH method to model a surge converter in 2D and 3D, comparing device motion and pressure values on the device surface to experimental results. [161] concludes that 3D simulations are crucial to accurately predict the rotation angle of, and the pressure on, the device. [167] studies two operational tests, a horizontal cylinder and a cone, using different codes (two different RANS codes, a Euler equation solver and a WCSPH model). Results are compared to experimental tests for the horizontal cylinder, for which the commercial RANS shows the best agreement, but all the codes return relatively accurate results. Finally, [168] analyses fixed and floating OWCs using a WCSPH model, where simulation results are compared to experimental tests. Results show good agreement with experimental values, demonstrating the success of SPH methods in simulating not only fixed, but also floating, OWCs, which may be more problematic in mesh-based CFD codes. 


\subsection{Potential flow models}

Potential flow models, also known as boundary element methods (BEMs), are based on the potential theory method, where the potential flow describes the velocity flow as the gradient of the velocity potential. This potential of the incident flow can be split into three different parts, following the linear assumptions described in Section 3.2.1, in order to study the water-body interaction: the undisturbed incident potential $\left(\Phi_{I}\right)$, the diffracted potential $\left(\Phi_{\text {diff }}\right)$ and the radiated potential $\left(\Phi_{\mathrm{rad}}\right)$. The incident, diffracted and radiated potentials together add the total potential of the incident flow $\left(\Phi_{t o t}\right)$.

Thus, the pressure of the total incident flow acting on the body can be obtained by deriving this total potential in Bernoulli's equation as follows,

$P=-\rho g z-\rho \frac{\partial \Phi_{t o t}}{\partial t}-\rho \frac{\left|\nabla \Phi_{t o t}\right|^{2}}{2}$

where $z$ is the position of the body and $\rho g z$ the hydrostatic pressure.

Following the division of the incident flow potential into three parts, the Bernoulli Eq. (6) can also be given as follows,

$$
\begin{aligned}
P= & -\rho g z-\rho \frac{\partial \phi_{I}}{\partial t}-\rho \frac{\left|\nabla \phi_{I}\right|^{2}}{2} \\
& -\rho \frac{\partial \phi_{\text {diff }}}{\partial t}-\rho \frac{\left|\nabla \phi_{\text {diff }}\right|^{2}}{2} \\
& -\rho \frac{\partial \phi_{\text {rad }}}{\partial t}-\rho \frac{\left|\nabla \phi_{\text {rad }}\right|^{2}}{2} \\
& -\rho \nabla \phi_{I} \nabla \phi_{\text {rad }}-\rho \nabla \phi_{I} \nabla \phi_{\text {diff }}-\rho \nabla \phi_{\text {diff }} \nabla \phi_{\text {rad }}
\end{aligned}
$$

Eq. (7) represents the pressure acting on the floating body and one can observe some nonlinearities, such as quadratic and second-order radiation-diffraction terms. This pressure is divided into different parts, where the composition of each component of the pressure and the corresponding force is presented in [26] for linear and partially nonlinear forces.

\subsubsection{Linear potential flow model}

For the linear case, the fluid is assumed to be inviscid and the incident flow irrotational and incompressible. Analysing only wavestructure interactions, the governing equation based on Newton's equation can be described as

$M \ddot{X}=F_{g}-\int_{S(t)} P d S$

where $F_{g}$ is the gravity force and $S(t)$ the time-varying wetted surface. The wetted surface is constant (the mean value is deployed) for the linear model, while the instantaneous wetted surface is calculated at each time-step for the partially nonlinear model. As the pressure acting on the body is divided as shown in Eq. (7), the Newton's Eq. (8) develops into (9), for the linear case, and into (10) for the partially nonlinear case.

Apart from computing the pressure over the mean wetted surface, the quadratic terms of Eq. (7) are neglected in the linear case, and so the governing linear equation develops into

$$
\begin{aligned}
M \ddot{X}= & K_{H} X-\int_{-\infty}^{\infty} K_{e x}(t-\tau) \eta(0,0, \tau) d \tau \\
& -\mu_{\infty} \ddot{X}-\int_{-\infty}^{\infty} K_{r a d}(t-\tau) \dot{X}(\tau) d \tau
\end{aligned}
$$

where $K_{e x}$ is the excitation force kernel, which involves diffraction and dynamic FK forces, and $K_{H}$ is the hydrostatic stiffness, that gives the relationship between the gravity force and the static pressure. The radiation force is expressed as a convolution product, based on the Cummins equation, where $\mu_{\infty}$ is the infinite frequency added mass parameter and $K_{r a d}$ the reduced radiation impulse-response function.

\subsubsection{Nonlinear potential flow models}

3.2.2.1. Partially nonlinear model. The partially nonlinear model is essentially an extension of the linear model, which considers some nonlinear effects by modifying the linear model. Two main extensions are found in the literature, where the first extension considers nonlinear Froude-Krylov forces and the second one allows a more precise computation of radiation-diffraction forces. [170] presents these two improvements for the SEAREV device and are then adapted to other types of device: a two-body heaving PA [31], a heaving sphere [32], or a cylinder [26].

The first improvement of the linear model includes nonlinear FK forces, calculated by integrating the pressure shown in Eq. (7), neglecting quadratic and second order terms, over the instantaneous wetted surface. In this first extension, static and dynamic FK forces are summed into the instantaneous FK force, but other forces such as radiation or diffraction remain linear and are computed separately, represented as:

$$
\begin{aligned}
M \ddot{X}= & F_{g}-\int_{S(t)}\left(P_{\text {stat }}+P_{d y n}\right) \vec{n} d S \\
& -\int_{-\infty}^{\infty} K_{d i f f}(t-\tau) \eta(0,0, \tau) d \tau \\
& -\mu_{\infty} \ddot{X}-\int_{-\infty}^{\infty} K_{\text {rad }}(t-\tau) \dot{X}(\tau) d \tau
\end{aligned}
$$

where $K_{\text {diff }}$ is the kernel for diffraction force.

The efficacy of the nonlinear computation of Froude-Krylov forces is, nevertheless, extremely sensitive to an accurate estimation of the instantaneous wetted surface, as panels in the border of the freesurface can be partly submerged and partly out of the water, leading to a missestimation of the instantaneous wetted surface. Therefore, different strategies to accurately estimate the wetted surface at each time-step are presented in the literature. [27] uses a very fine mesh, taking into account only those cells below the instantaneous freesurface at each time-step. On the other hand, [27,31,32] use a remeshing routine, modifying those cells of the mesh being partly submerged and partly out of the water.

It is the estimation of the instantaneous wetted surface which requires extra computational efforts, and so is important to select the most efficient technique. [27] compares both strategies, the fine mesh and the remeshing routine, for the same device and the same simulation conditions, and both appear to accurately estimate the wetted surface at each time-step. However, the technique using a very fine mesh seems to require computationally less efforts.

For axisymmetric devices, an alternative solution to compute FK forces over the instantaneous wetted surface is suggested in [171] based on the algebraic solution, which substantially reduces computation requirements for the same accuracy of the very fine mesh or the method with the remeshing routine [86].

The second extension adds another degree of complexity to extend the linear approach and improves the accuracy of the results. In this case, a more precise computation of hydrodynamic forces, including nonlinear radiation-diffraction, is presented.

This development can be overtaken using two different approaches: expanding the forcing terms around the mean wetted surface or directly expanding the equation of the hydrodynamic force. The expansion to the second order is carried out in two steps, where the linear hydrodynamic force is developed to the second order in the first step and the quadratic terms of the Bernoulli's equation are added in the second.

The first extension considerably improves the results by considering nonlinear FK forces, while the second extension makes little difference, al least for devices considerably smaller than the wavelength, as seen in Section 2.2.8. However, the second extension requires a recalculation of the hydrodynamic parameters at each sampling instant, resulting in a high computational overhead. In addition, there exist other nonlinear 
effects such as viscous effects and other external forces (e.g. PTO force) that need to be computed as external forces by extending the linear model. Section 3.2.3 presents different methods to consider viscous effects in a potential flow model.

3.2.2.2. Weakly nonlinear model. While the partially nonlinear models' objective is to improve the linear one, the approach pursued by the so called weakly nonlinear models is to simplify the fully nonlinear formulation. A perturbation expansion of the equations describing the interactions between waves and structure is performed with respect to the wave steepness $k A$ and the boundary conditions are approximated by their Taylor expansion. The perturbation method solves for the lowest degree of steepness and uses the results as an input for the higher degree terms. Typically a second order approximation is used, where the (linear) solution in $k A$ is used to solve for $(k A)^{2}$. Different codes which use a second order approximation are able to more effectively describe the diffraction and the excitation problem $[172,173]$.

An alternative approach to simplify the fully-nonlinear problem is the weak-scatterer approximation [174], which assumes the perturbation potential (composed by radiation and diffraction potential) small compared to the incident potential. Such an approximation is valid for bodies whose characteristic dimension is much smaller than the wave length. The boundary value problem is then solved iteratively on the exact free surface elevation and the instantaneous wetted surface.

3.2.2.3. Fully nonlinear model. When the sea conditions exceed the power production mode, any simplification of the complete model becomes unacceptable and the only way to describe the response of the device in extreme conditions is to consider all the nonlinearities. Keeping in mind that, with a potential flow method, viscosity is not included, as well as effects like green water, slamming or sloshing, in the presence of large waves the results are very accurate thanks to the calculation of the exact instantaneous boundary conditions. Therefore, fully nonlinear potential flow models have been used effectively to simulate Numerical Wave Tanks in 2D by Guerberg [175] and 3D by Grilli [176].

Weakly nonlinear and fully nonlinear potential flow models are both in an early stage of development and so further research is necessary to extract some more definitive conclusions. [177] presents a comparison of the weakly and fully nonlinear models analysing a fully submerged cylinder, whose conclusion is that both methods give a good agreement in the hydrodynamic coefficients. Although the low complexity of the analysis is recognised (a fully submerged cylinder), it remarks that expectations have been met with both methods. A final table summarising main characteristics of each method highlights the much higher computational requirements of the fully nonlinear method.

CFD and potential flow methods are presented in Sections 3.1 and 3.2 , respectively, as individual approaches, but some studies in the literature suggest they might be combined in order to take advantage of the benefits of each of the methods.

The SWENSE method presented in Section 3.1.2 is one of the existing codes in this sense, used in [178] to simulate the CALM buoy in regular and irregular seas. In [179], a fully nonlinear potential flow solver was combined with a fully nonlinear Navier-Stokes VOF solver by an efficient and geometrically flexible one-way coupling method. Different tests for surface piercing circular cylinders were simulated with a good agreement between the code and experimental results. Another alternative was presented in [180], coupling a linear BEM code, $\mathrm{NEMOH}$, with a finite element analysis (FEA) tool, CodeAster, to analyse numerical vibration of an oscillating surge converter. Hydrodynamic coefficients, with special interest in the added mass, are first computed by the linear BEM method for different rates of immersion and then used in the numerical vibrational analysis, considerably reducing the required computational effort. Results obtained from the coupling methodology are compared to experimental results, returning good results and proving its functionality.

\subsubsection{Viscous effects in potential flow models}

Viscous effects are completely neglected by linear potential flow models, as the fluid is considered inviscid. However, their relevance has been demonstrated in Section 2.2.8, suggesting viscous effects should be externally included.

There exist two main methods to externally include viscous losses into potential flow models: using an additional linear damping or through the Morison equation [181] using a quadratic viscous term. The most widely used method in wave energy and other offshore applications is the Morison form expressed as follows,

$F_{\text {vis }}=-\frac{1}{2} \rho A C_{D} \dot{X}|\dot{X}|$

where $\rho$ is the water density, $A$ the cross-sectional area and $C_{D}$ the viscous drag coefficient.

The nature of viscous drag is nonlinear and can only be identified when using wave tank experiments $[27,182,59,93]$ or fully viscous modelling methods that are generally based on Navier-Stokes equations: Numerical wave tank (NWT) simulations implemented in computational fluid dynamic (CFD) codes $[87,28]$ or some other specific hydrodynamic codes $[83,27]$.

Drag coefficient values used in different studies come from the offshore industry publications [183] or identification procedures with fully nonlinear methods $[87,28]$ or experimental tests $[184,185]$. The discrepancies between different studies, however, lead to a dangerous uncertainty. As an example of the uncertainty, drag coefficients for OSCs found in the literature can vary from 1.9 [28] to 8 [186].

\subsection{Models from data}

Sometimes, the physical system being analysed is so complex, that it can be practically impossible to create a model considering all the components that comprise the 'system', or is so complex that the model requires enormous computational effort.

In such cases, alternative modelling approaches, successfully tested in other fields, can be used. Models from data, which are well established, for example, in the control system community, where complex models are determined by input/output data, can be a solution. Hence, the model is based on the data rather than the physical process, as happens in conventional models. System identification models use statistical methods to build mathematical models of dynamic systems from measured data, which is particularly interesting for very complex systems, where the physical principles are too complicated to formulate.

Every identification method consists basically of.

- Conducting a series of representative tests on the 'system',

- selecting a series of representative data of the 'system' to be reproduced,

- determining the structure of the model (model type and order, nonlinear terms, etc.),

- defining the fitting criteria, and

- using numerical optimization to identify the system parameters.

Thus, there are three key elements in system identification: the representative data, the model structure and the identification algorithms.

Using representative data of the system dynamics that entirely covers the whole range of frequencies/amplitudes the system is likely to deal with is crucial. In the particular case of hydrodynamic 
applications, such data can be obtained from wave tank experiments $[187,188]$. However, extracting representative data from wave tank experiments may be problematic, because it is not always easy to isolate the required data due to the limitations on the range of excitation signals or the tank wall reflections. Data can also be extracted numerical wave tank simulations implemented in BEM or CFD codes $[115,189,190]$.

Numerical wave tank simulations have certain advantages compared to experimental tests, because intermediate variables, such as excitation force, can be measured. Besides the access, measurements are accurate in NWT simulations, since there is no reflection effect or measurement noise, as in experimental tests. Moreover, NWT simulations are fully nonlinear simulations, so the results generally show good agreement with the experimental tests. The main disadvantages of NWT simulations are the computational requirement, as mentioned in Section 3.1, and the uncertainty of the results accuracy without any validation.

In order to generate adequate data for the identification of model parameters, various experiments can be carried out to provide data of different characteristics. The simplest possible experiment is the free decay test (no external input) [189], where the fundamental dynamic parameters of the system, such as natural frequency, can be identified. A test with input waves (free surface elevation as input) is another possibility, where the output can be body motion, position and/or velocity, or excitation force [191]. An external force (e.g. PTO force), can also be used as input, with the device motion as the measured output [190]. In the case of the input wave test, the input signal is limited by different factors, e.g. wave steepness, while, in input force test, one has total freedom of excitation signal shape choice. Finally, prescribed motion tests can also be used, where the device is forced to follow a predetermined path while measuring the fluid force on the device [115].

Once the data is generated, the structure of the model must be determined, which is probably the key point in order to create a representative model. The majority of system identification techniques are based on discrete-time models [192], which can be of very diverse form. The choice of the mode structure essentially depends on the features of the system. If the system to be reproduced is considered linear, an autoregressive with exogenous input (ARX) model can be suitable, where only $n_{a}$ and $n_{b}$ need to be specified in Eq. (12).

$y(k)=\sum_{i=1}^{n_{a}} a_{i} y(k-i)+\sum_{i=0}^{n_{b}} b_{i} u\left(k-n_{d}-i\right)$

However, the ARX mode cannot capture nonlinear behaviours, and is therefore excluded. In order to capture nonlinear effects, nonlinear autoregressive with exogenous input (NARX) models are suggested [193], where the present output depends on the past (and future if the system is noncausal, $n_{d}<0$ ) output values and the input values. Fig. 9 illustrates a general block diagram for NARX models, where $n_{a}$ and $n_{b}$ represent the order of the model and $n_{d}$ the input delay.

There are several possibilities of model structures, g[] in Fig. 9, from a structure based on the knowledge of the physical principals of the system (white-box) to a structure completely ignorant of these principals (black-box) [192]. Apart from the model structure, the way to analyse the nonlinearities (the form) and its complexity need also to be selected.

Some model structures for nonlinear modelling of the wave energy converters and their capabilities are presented in the following subsections.

\subsubsection{Hammerstein/Wiener model}

Nonlinear input/output relationship can be modelled by using a simple nonlinear static block $(r())$. This static block can be used in combination with a linear ARX model obtaining a nonlinear model structure. Depending on the number of static blocks and their config-

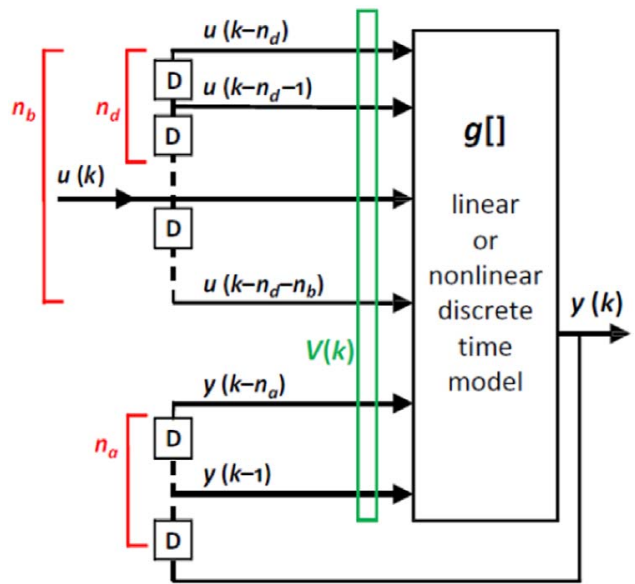

Fig. 9. Block diagram of a general NARX discrete-time model.

uration, different model structures can be formed.

In the Hammerstein model, the nonlinear static block is connected in cascade with the linear ARX block, as illustrated in Fig. 10 (a). As a consequence, the relationship between the input and output is given by the product of $s(k)$ and the steady-state gain of the ARX model [194]:

$y(k)=\sum_{i=1}^{n_{a}} a_{i} y(k-i)+\sum_{i=0}^{n_{b}} b_{i} r\left(u\left(k-n_{d}-i\right)\right)$

A Wiener model is regarded as the dual of Hammerstein model [195], and both are considered grey-box models. Grey-box models combine a partial theoretical structure with data to complete the model.

\subsubsection{Feedback block-oriented model}

In the case of the feedback block-oriented model, illustrated on the right of the Fig. 10, the structure is characterized by a negative feedback [194], where the static nonlinear block $(h())$ is placed in the feedback path, between the input and the output. Feedback blockoriented model is also a grey-box model and the input/output relationship is again nonlinear and is given as follows,

$y(k)=\sum_{i=1}^{n_{a}} a_{i} y(k-i)+\sum_{i=0}^{n_{b}} b_{i} r\left(e\left(k-n_{d}-i\right)\right)$

where

$e(k)=u(k)-h(y(k))$

The Hammerstein and feedback block-oriented models are nonlinear in input/output relationship, but linear in parameters. [115] uses a Hammerstein and a feedback block-oriented model for a heaving device using an external force as input. The heaving device is a vertical cone, which in theory implies, at least, a nonlinear restoring force. In addition, NWT simulations provide data where the body motion is large enough to exhibit nonlinear effects.

Apart from the parameters of the ARX model component in Fig. 10, the static block must be identified. In [115], the static block for the Hammerstein and feedback block-oriented models is identified using a predefined motion experiment in a NWT, slowly moving the device from fully submerged to fully dry positions and measuring the fluid force. Moving the device sufficiently slowly, the measured fluid force is assumed to be a hydrostatic force. Hence, a physical interpretation for the static block is possible in both models. For the Hammerstein model, $r$ () can be interpreted as the inverse of the restoring force, while in the feedback block-oriented model, $h()$ is the negative of the restoring force.

Besides the Hammerstein and feedback block-oriented models, an ARX model is studied on the data containing significant nonlinear behaviour in [115]. While the ARX is unable to capture the nonlinear 


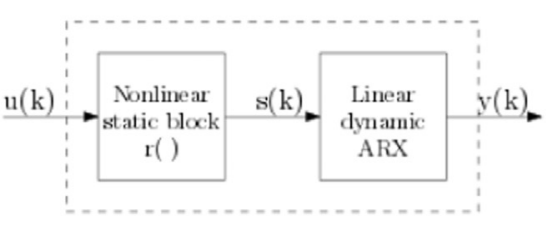

(a)

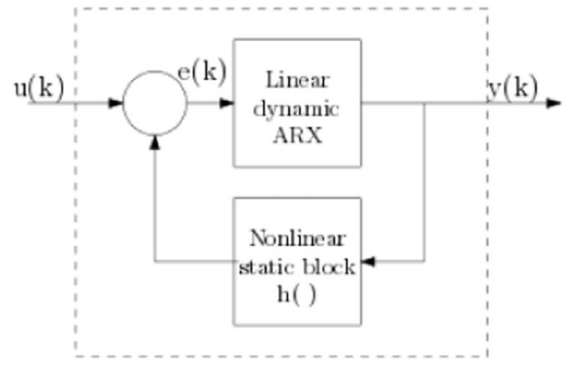

(b)

Fig. 10. Hammerstein (a) and feedback block-oriented (b) model structure diagrams, modified from [115].

behaviour, which is to be expected, both the Hammerstein and the feedback block-oriented models show excellent agreement in reproducing the asymmetrical steady-state response. In this specific example, the feedback block-oriented model performed particularly well.

\subsubsection{Kolmogorov-Gabor polynomial model}

The Kolmogorov-Gabor Polynomial (KGP) model is a black-box model that uses polynomial nonlinearities to describe the input/output relationship of the data [193]. Despite the nonlinear input/output relationship, the KGP model is linear in the parameters, as shown in Eq. (16), which allows a fast identification.

$$
\begin{aligned}
y(k)= & \sum_{i=1}^{n_{a}} a_{i 1} y(k-i)+\sum_{i=1}^{n_{b}} b_{i 1} u\left(k-n_{d}-1\right)+\ldots \\
& +\sum_{i=1}^{n_{a}} a_{i p} y^{p}(k-i)+\sum_{i=1}^{n_{b}} b_{i p} u^{p}\left(k-n_{d}-1\right) \\
& +\sum_{i=1}^{n_{a}} \sum_{j=0}^{n_{b}} c_{i j} y(k-i) u\left(k-n_{d}-j\right)+\ldots
\end{aligned}
$$

where $p$ is the highest polynomial order and $a_{i j}, b_{i j}$ and $c_{i j}$ are the model parameters. Because KGP is a black-box model, the parameters have no physical meaning.

[196] studies a heaving floating body with a KGP model using data from NWT tests. The cross product terms, involving $u$ and $y$, in Eq. (16) are removed to avoid instabilities, and a polynomial order (p) of 2 is selected. The agreement with the NWT data is good, both in training and validation. Structures with higher polynomial orders are found to improve the results on the training data, but reduce the performance on the validation data, suggesting overfitting. A linear ARX model is also studied on the same data in [196], showing very similar performance to the KGP model, which indicates that the data employed probably does not include much nonlinear behaviour. Significantly, the excitation in this case come only from a wave input (no PTO/external input).

\subsubsection{Artificial neural networks}

Artificial Neural Networks (ANNs) are systems of interconnected neurons, simple artificial nodes, that consist of sets of adaptive weights and are capable of approximating nonlinear functions of their inputs. The adaptive weights specify the connection strengths between neurons.

There exist several types of ANNs structures used in different applications. The model suggested in [190] is a multilayer perceptron (MLP) ANN, which is a black-box model with a nonlinear input/output relationship and is nonlinear in the parameters. This latter characteristic makes it different from any other model structure suggested in this section and makes the identification process difficult, since local minima can be found in the parameter optimization problem.

Hence, through the modelling procedure, different conditions, such as the number of layers, the number and type of neurons in each layer or the delayed input and output values, must be determined to define the required structure of the ANNs. The complexity of a MLP model is determined by the number of neurons in each hidden layer in addition to $n_{a}$ and $n_{b}$. Assuming two hidden layers, the input/output relationship is given as follows

$y(k)=\sum_{i=0}^{n_{2}} \omega_{i}^{(\text {out })} \Psi_{i}\left(\sum_{j=0}^{n_{1}} \omega_{i j}^{(2)} \Psi_{j}\left(\sum_{l=0}^{n_{v}} \omega_{j l}^{(1)} v_{l}(k)\right)\right)$

where $\omega_{i}^{(\text {out })}, \omega_{i}^{(1)}$ and $\omega_{i}^{(2)}$ are the unknown parameters of the output layer and the first and second layers, respectively, and $\Psi_{i}$ is the activation function. The role of this activation function in a ANN is to produce a nonlinear decision boundary via nonlinear combinations of the weighted inputs. In [190] a tansigmoidal activation function is chosen to provide global support and a smooth interpolation.

[190] uses a NWT model to generate data, where three identification tests are performed: one with purely wave excitation (irregular sea-state) and two types of direct force inputs (chirp and random amplitude random period (RARP)). When identifying the parameters for a model relating free surface elevation to device motion (wave excitation input), because the relationship between the two is noncausal, an additional step to measure the noncausal advance must be taken.

The results of the ANN model for the wave excitation input shows very good agreement on the training data, but loses performance in the validation test, similarly to the overfitted KGP model in [196]. The degradation in validation performance is seen by the authors as a consequence of the nonlinear optimization with many local minima, which demonstrates the complexity associated with the nonlinear identification of ANN models.

The performance of the models presented in this section, regardless of the model structure, is limited to the data the models are identified from, so that the scope of validity of the models relies entirely on the data they are trained on.

A comparative study of all the nonlinear approaches analysed in Section 3 is shown in Table 3, where the fluid and hydrodynamic models, the expected accuracy and computational cost or the main advantages or drawbacks of each method are evaluated. It should be noted that all the characteristics are not applicable to all the methods, e.g. the ANN model does not use any fluid or hydrodynamic model, which is solved by using the N/A abbreviation that means not applicable. In addition, the capabilities of models from data are still untapped due to the lack of serious validation. Therefore, the Accuracy column in Table 3 reads $N / I$, which means not enough information is available.

\section{Discussion}

The different modelling approaches evaluated in Section 3 showed the ability to deal with different nonlinear effects and the relevance of different nonlinear effects is demonstrated to vary with the WEC type in Section 2.2.8. Thus, a model that efficiently deals with the relevant nonlinear effect can be chosen for each WEC type. However, the selection of an efficient modelling approach includes an additional 


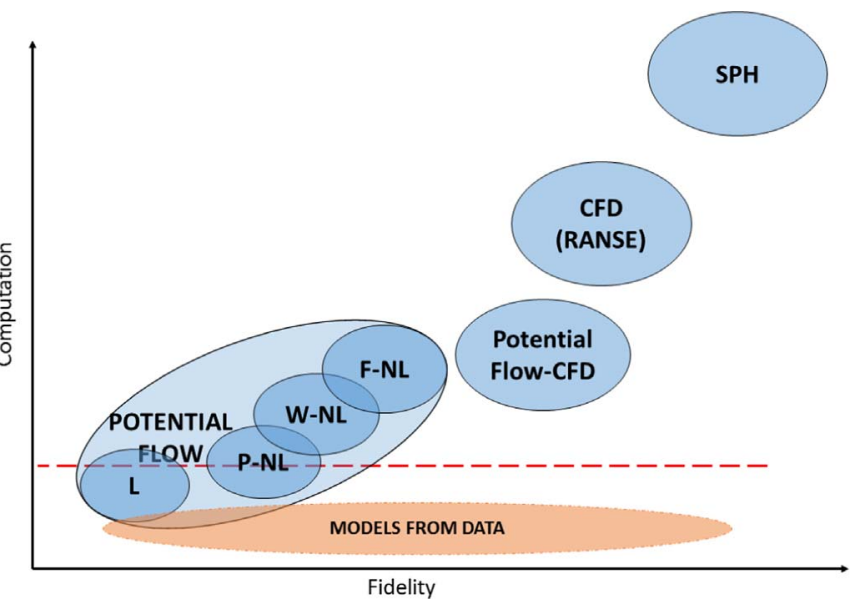

Fig. 11. The computation/fidelity compromise of the different modelling approaches evaluated in Section 3. L means linear, P-NL means partially-nonlinear, W-NL means weekly-nonlinear and F-NL means fully-nonlinear. The red dashed horizontal line represents the affordable computation limit for models with low computation requirements.

essential variable: model purpose. All the possible purposes of a mathematical model in wave energy, e.g. power production assessment, model-based control, optimization, simulation of device motions or structural analysis, can be divided into two groups with a distinguishing dominant requirement: computation vs. fidelity (accuracy). Fig. 11 illustrates the compromise between computation and fidelity of the modelling approaches described in Section 3.

Models for power production assessment, model-based control or optimization, require low computation time (with a reasonable fidelity), because a large amount of cases need to be studied. In the case of model-based control, apart from the computation, the structure of the model is also important, being able to turn the model into a control calculation. The red dashed line in Fig. 11 represents the limit of the maximum affordable computation for models with low computation requirements.

In contrast, models for device behaviour simulation or structural analysis require high fidelity, because they are crucial in the final device design process, which is one of the key cost drivers for WECs. CFD models are most commonly used in this context, in spite of their high computation requirements. A solution to reduce computation costs without losing fidelity can be the combined potential flow-CFD approaches.

In the case of OWCs, viscosity effects appear to be significantly more important than potential flow nonlinearities. The predominant viscosity effects, the separation and vortex generation at the front wall, combined with the two-phase problem, makes the CFD approach ideal for high fidelity studies of OWCs. Fixed OWCs are relatively easy to model in CFD, since a 2D model can be accurate enough and especially because no dynamic mesh is required. CFD has been presented as the solution for OWCs, validating simulation results against tank experiments, in [197] or [62] where the vortex generation at the front wall of the device is studied, in [198] where the nonlinear behaviour of the water column in the chamber is predicted, or in [199] where the viscous effects at the entrance of the chamber are found responsible for the efficiency decrease.

$3 \mathrm{D}$ models have also been utilized in the literature, where results are compared to 2D models and experimental results, for example in [200] and [201]. 3D models appear to be more accurate than 2D models, although simulation conditions were not exactly the same. However, computation cost also increases substantially from 2D to 3D simulations.

Floating OWCs include an additional difficulty into the problem: the dynamic mesh. The motion of the device makes the use of dynamic 
mesh indispensable, which complicates the simulation and increases even more the computation. [128] presents a 2D simulation of a heaving-only floating OWC, where the effect of mooring elasticity, the pneumatic damping and frequency have significant impact on the results. SPH meshless models can be an alternative to avoid dynamic meshes in floating OWCs [168]. Unfortunately, the computational cost of SPH models is still prohibitive.

In HPAs, the relevance of viscous effects is demonstrated to be low, as shown in Table 2, so potential flow nonlinearities become dominant. Therefore, nonlinear potential flow approaches are a suitable solution. The fact that nonlinear radiation and diffraction appear to be negligible $[31,32]$ and the main nonlinear effects arise from nonlinear FroudeKrylov forces $[26,86,60]$, partially nonlinear approaches suit ideally, which is also convenient in terms of computational requirements. CFD approaches provide marginally higher fidelity [202,203] compared to potential flow models, but the excessive additional computation cost is hardly justified by the differences in the results. [86] demonstrates for a heaving sphere with latching control, an experiment where substantial nonlinear dynamics are present, that a partially nonlinear potential flow with an externally added viscous drag provides very high fidelity. Although CFD provides slightly higher fidelity, the computation time is several order of magnitudes higher.

OPCs are in between those of OWCs and HPAs, where both potential flow nonlinearities and viscous effects are equally important. In fact, [27] demonstrates that a partially nonlinear potential flow model is able to predict parametric excitation, but not the correct motion amplitude. Therefore, [27] suggests a code that combines a nonlinear potential flow method to account for the incident wave and a CFD (RANS) model for the scattering and viscous effects. Hence, the computation is reduced while the fidelity of the results is improved substantially. Note that HPAs with damping plates may be considered as OPCs due to the higher relevance of viscous effects compared to HPAs without a damping plate [204,205].

Finally, OSCs appear to be dominated by viscous losses and radiation/diffraction forces. [206] suggests viscous losses may be dominant for bottom-hinged OSCs with no peak in the capture factor. Same statement is also held in [28], where a power loss of over $30 \%$ due to viscous effects is presented. However, [207] concludes that the Oyster OSC is definitely diffraction dominated and [88] describes OSCs as radiation/diffraction dominated.

The highly nonlinear but typical slamming events in OSCs [92] added to the above mentioned relevance of viscous losses and radiation/diffraction forces suggest that CFD approaches, that consider the entire flow field, may be ideal. CFD codes have often been used to model OSCs using 2D $[92,130]$ and 3D simulations $[129,28]$, provided with dynamic mesh capabilities, giving good agreement with experimental tests.

Apart from the HPAs, with the exception of HPAs with damping plate, the relevance of the nonlinear effects presented in Section 2.2.8 implies the need of CFD models, either CFD alone or combined with potential flow methods, as shown in Table 4. Despite the constant improvement of computational power of computers and the refinement of the CFD approaches, CFD is still a computationally expensive solution and lays far from the affordable limit, the red horizontal dashed line, in Fig. 11. Therefore, alternative less accurate but faster solutions are necessary for those models with low computation requirements.

As shown in Fig. 11, the only approaches within the affordable computation region delimited by the red dashed line are the linear and partially nonlinear potential flow models and the models from data. The latter approaches can be highly interesting with really low computation requirements and potentially able to provide high fidelity results. However, models from data are still in an early stage of development regarding wave energy, and, as a consequence, real capabilities of data-based models are still unknown. That is the reason why the models from data box is shown in a different colour in Fig. 11.
Table 4

Suggested modelling approaches for models with high fidelity requirements.

\begin{tabular}{|c|c|}
\hline & $\begin{array}{l}\text { High fidelity } \\
\text { (Simulation of device behaviour/Structural analysis) }\end{array}$ \\
\hline OWC & $\operatorname{CFD}^{* * * * *}[197,62,199,128]$ \\
\hline HPA & Partially nonlinear potential theory with viscous drag ${ }^{* * *}[86,60,204]$ \\
\hline OPC & Partially nonlinear potential theory combined with CFD [27] \\
\hline OSC & $\operatorname{CFD}^{* * * * *}[130,28,129,92]$ \\
\hline
\end{tabular}

* OPCs in this table include self-reacting HPAs with damping plates.

** While CFD provides marginally better fidelity than partially nonlinear potential theory [202,203], the excessive additional computation cost demanded is hardly justified by the differences in the results [86].

The additional computation of SPH models can be justified under specific (extreme) conditions in OWCs [168] or OSCs [65,163], but not in models for WECs operating in the power production mode.

Hence, despite the different requirements presented in Section 2.2.8 for each WEC type, the modelling possibilities are reduced to two options: linear and partially nonlinear potential flow models. In the benchmarking study carried out in [186], different devices are evaluated using linear potential flow with viscous drag, which is the most commonly used approach in the literature. However, including nonlinear Froude-Krylov forces by means of the partially nonlinear potential flow approach is recommendable for all the WECs, except for OSCs, for which the relevance of nonlinear FK forces is determined to be negligible. The viscous drag can be included in all the cases, since no extra computation cost is required.

Suggested modelling approaches for models with low computation requirements are shown in Table 5 for each WEC type. The literature shows examples of the suggested approaches for all the WEC types (HPAs [86,60,204], OPCs [27] and OSCs [206]) except for OWCs. However, [59] compares experimental tests for an axisymmetric floating OWC with results from a model based on linear potential flow without viscous drag. The authors conclude that a better agreement was not possible due to viscous effects (ignored in the model) and the Mathieu-type instabilities. The issue with viscous effects can be partly solved including a carefully identified drag coefficient, while the instabilities can be predicted by including nonlinear FK forces. Therefore, the partially nonlinear model with viscous drag suggested in Table 5 for OWCs appears to be a good solution.

SPH models have not been suggested for any of the WEC types in the present paper. SPH is an interesting approach that may have some advantages compared to the traditional mesh-based CFD codes, such as the efficient treatment of the large deformation of the free surface handling complex boundary evolution or the natural distinction between different phases. However, the computational cost is still prohibitive, reducing its application range to very specific situations, such as extreme loading and impact events [169,65,208,163,162].

\section{Conclusion}

Due to a wide variety of devices and the lack of a predominant concept to focus on (compared, for example, to the 3-bladed horizon-

Table 5

Suggested modelling approaches for models with Low computation requirements.

Low computation

(Power assessment/Model-based control/Optimization)

\begin{tabular}{ll}
\hline OWC & Partially nonlinear potential theory with viscous drag \\
HPA & Partially nonlinear potential theory with viscous drag [86,60,204] \\
OPC & Partially nonlinear potential theory with viscous drag [27] \\
OSC & Linear potential theory with viscous drag [206]
\end{tabular}

OPCs in this table include self-reacting HPAs with damping plates. 
tal-axis turbine typical in the wind industry), mathematical modelling of wave energy converters becomes highly device-dependent, where each concept has particular modelling requirements.

Linear models cover the vast majority of the WEC models documented in the literature, mainly due to the appealing computational requirements. However, the relevance of nonlinear effects has been demonstrated in the literature for a wide variety of WECs, as shown in Section 2.2.8. Although nonlinear effects may be highly device-dependent, a classification based on the relevance of nonlinear effects is given in the present paper, suggesting a specific modelling approach for each WEC type. However, most of the nonlinear approaches require high computational resources, which may be incompatible with the purpose of the model.

Considering the different model purposes in wave energy, two dominant requirements have been identified: computation vs. fidelity. The dominant requirement for models for power production assessment, optimization or model-based control is low computation (with a reasonable accuracy), while models for simulation of the device behaviour or structural analysis over short timescales require high fidelity and can afford higher computations. Hence, modelling approaches have been suggested for different purposes and WEC types.

In the case of models with high fidelity requirements, CFD models are the most suitable options, either CFD alone or coupled to a potential flow model, for all the WEC types except for heaving points absorbers, for which nonlinear potential theory appears to be sufficiently accurate. SPH methods have some benefits compared to CFD, but can be computationally prohibitive.

In contrast, models with low computational requirements are necessarily based on potential flow methods, either linear or partially-nonlinear, due to the excessive computational costs of fully nonlinear approaches. Models from data, such as KGP or ANN models, appear to be promising alternatives, but they are still in an early stage of development.

\section{Acknowledgment}

This paper is based upon work supported by Science Foundation Ireland under Grant No. 13/IA/1886.

\section{References}

[1] Mork G, Barstow S, Kabuth A, Pontes M. Assesing the global wave energy potential. In: Proceedings of the 29th International Conference on Ocean, Offshore Mechanics and Artic Engineering (OMAE), China, 2010.

[2] Salter SH. Wave power. Nature 1974;249:720-4. http://dx.doi.org/10.1038/ $249720 \mathrm{a} 0$.

[3] Kramer M, Marquis L, Frigaard P. Performance evaluation of the wavestar prototype. In: Proceedings of the 9th European Wave and Tidal Energy Conference: EWTEC 2011, 2011.

[4] Whittaker T, Collier D, Folley M, Osterried M, Henry A, Crowley M. The development of oyster: a shallow water surging wave energy converter. In: Proceedings of the 7th European Wave and Tidal Energy Conference, Porto, Portugal, 2007, p. 11-14.

[5] Henderson R. Design, simulation, and testing of a novel hydraulic power take-off system for the pelamis wave energy converter. Renew Energy 2006;31(2):271-83.

[6] Mann L, Burns A, Ottaviano M. Ceto, a carbon free wave power energy provider of the future. In: Proceedings of the 7th European Wave and Tidal Energy Conference (EWTEC), 2007.

[7] Oceanlinx, www.oceanlinx.com.

[8] Salcedo F, Ruiz-Minguela P, Rodriguez R, Ricci P, Santos M. Oceantec: sea trials of a quarter scale prototype. In: Proceedings of the 8th European Wave Tidal Energy Conference, 2009, p. 460-5.

[9] Mekhiche M, Edwards KA. Ocean power technologies powerbuoy ${ }^{\circledR}$ : System-level design, development and validation methodology. In: Proceedings of the 2nd Marine Energy Technology Symposium, METS, Seattle (WA), 2014.

[10] Kofoed JP, Frigaard P, Friis-Madsen E, Sørensen HC. Prototype testing of the wave energy converter wave dragon. Renew Energy 2006;31(2):181-9.

[11] Falcao A. The shoreline owc wave power plant at the azores. In: In Proceedings of the 4th European Wave Energy Conference, 2000

[12] Whittaker T, Lewis A, Thomas G. Performance of the limpet wave power plant prediction, measurement and potential. In: Proceedings of the 5th European Wave Energy Conference, 2003.

[13] Torre-Enciso Y, Ortubia I, de Aguileta L. López, Marqués J. Mutriku wave power plant: from the thinking out to the reality. In: Proceedings of the 8th European Wave and Tidal Energy Conference, 2009, p. 319-329.

[14] Ocean energy, http://oceanenergy.ie/.

[15] McCormick M, Murthagh J, McCabe P. Large-scale experimental study of a hinged barge wave energy conversion system. In: Proceedings of the 3rd European Wave Energy Conference, 1998.

[16] Clément A, Babarit A, Gilloteaux J-C, Josset C, Duclos G. The searev wave energy converter. In: Proceedings of the 6th Wave and Tidal Energy Conference, Glasgow, UK, 2005.

[17] Waveroller, URL: 〈http://aw-energy.com/〉.

[18] Mehlum E. Hydrodynamics of Ocean Wave-Energy Utilization. Chapter 3 , TAPCHAN, Springer, 1986.

[19] Boletin de inteligencia tecnologica. tecnologias para el aprovechamiento de la energia de las olas y de las corrientes marinas., Tech. rep., Fundacion INNOVAMAR (2009).

[20] Matters ME. Marine energy, global development review 2011, Tech. rep., Marine Energy Matters (2011).

[21] Falcao AFdO. Modelling and control of oscillating-body wave enrgy conberters with hydraulic pto and gas accumulator, Ocean Engineering.

[22] Babarit A, Clément AH. Declutching control of a wave energy converter. Ocean Eng 2009;36:1015-24.

[23] Bacelli G, Ringwood J. Nonlinear optimal wave energy converter control with application to a flap-type device. In: Preprints of the 19th World Congress, The International Federation of Automatic Control (IFAC), Cape Town, 2014, p. 76967701.

[24] Lawson M, Yu Y-H, Nelessen A, Ruehl K, Michelen C. Implementing nonlinear buoyancy and excitation forces in the wec-sim wave energy converter modeling tool. In: ASME 2014 Proceedings of the 33rd International Conference on Ocean, Offshore and Arctic Engineering,San Francisco, CA, American Society of Mechanical Engineers, 2014.

[25] Yu Y-H, Li Y. Reynolds-averaged navier-stokes simulation of the heave performance of a two-body floating-point absorber wave energy system. Comput Fluids 2013;73:104-14.

[26] Peñalba M, Merigaud A, Gilloteaux J-C, Ringwood J. Nonlinear froude-krylov force modelling for two heaving wave energy point absorbers, in: In Proceedings of European wave and tidal energy conference, Nantes, 2015.

[27] Babarit A, Laporte-Weywada P, Mouslim H, Clement AH. On the numerical modelling of the nonlinear behaviour of a wave energy converter. In: Procedings of the ASME Proceedings of the 28th International Conference on Ocean, Offshore and Artic Engineering, Honolulu, OMAE, , vol. 4, 2009, p. 1045-1053. http://dx. doi.org/doi:10.1115/OMAE2009-79909.

[28] Bhinder M, Babarit A, Gentaz L, Ferrant P. Effect of viscous forces on the performanco of a surging wave energy converter. In: Proceedings of the 22nd International Offshore and Polar Engineering Conference, 2012.

[29] Asmuth H, Schmitt P, Henry A, Elsaesser B. Determination of non-linear damping coefficients of bottom-hinged oscillating wave surge converters using numerical free decay tests, 2014.

[30] Peñalba M, Mérigaud A, Gilloteaux J-C, Ringwood J. Modelling nonlinear froudekrylov forces for non-controlled and controlled heaving wave energy point absorbers in nonlinear waves, Renewable Energy.

[31] Gilloteaux, J-C, Bacelli G, Ringwood J. A nonlinear potential model to predict large-amplitude-motions: Application to a multy-body wave energy converter. In: Proceedings of the 10th World Renewable Energy Conference, Glasgow, 2008.

[32] Merigaud A, Gilloteaux J, Ringwood J. A nonlinear extension for linear boundary element method in wave energy device modelling. In: Proceedings of the 31st International Conference on Ocean, Offshore and Artic Engineering (OMAE), Rio de Janeiro, 2012, p. 615-621.

[33] Vicente P, Falcao A. Nonlinear slack-mooring modelling of a floating two-body wave energy converter. In: Proceedings of the 9th European Wave and Tidal Energy Conference (EWTEC), Southampton, 2011.

[34] Vicente P, Falcao A, Justino P. Nonlinear dynamics of a tightly moored pointabsorber wave energy converter, Ocean engineering.

[35] Clément AH. Non-linearities in wave energy conversion. In: Proceedings of the 4th Maynooth University Wave Energy Workshop (January 2015) URL:(http://www. eeng.nuim.ie/coer/view_event.php?Id=EV009).

[36] O'Boyle L, Doherty K, van't Hoff J, Skelton J. The value of full scale prototype data-testing oyster 800 at emec, orkney. In: Proceedings of the 11th European Wave and Tidal Energy Conference, Nantes, France, 2015.

[37] Reeve D, Chen Y, Pan S, Magar V, Simmonds D, Zacharioudaki A. An investigation of the impacts of climate change on wave energy generation: The wave hub, cornwall, \{UK\}. Renew Energy 2011;36(9):2404-13, [URL: 〈http://www. sciencedirect.com/science/article/pii/S096014811100111X http://dx.doi.org/ http://dx.doi.org/10.1016/j.renene.2011.02.020)].

[38] Sea Power, Seapower platform power matrix, Available at $\langle$ http://www.seapower. ie/wp-content/uploads/Seapower-Powermatrix.png $\rangle(09$ 2016).

[39] FLOW Science, Waves, Available at URL: 〈https://www.flow3d.com/home/ resources/modeling-capabilities/water-environmental-models/waves $\rangle(09$ 2016).

[40] Stokes G, On the theory of oscillatory waves, Transactions of the Cambridge Philofophical Society 8 (1847) 441-455, reprinted in: Stokes, G.G. (1880). Mathematical and Physical Papers, Volume I, Cambridge University Press. p. 197229.

[41] Fenton J. The Sea, Vol. 9, Wiley, New York, 1990, Ch. Ocean Engineering Science, Part A, p. 3-25.

[42] Fenton J. A high-order cnoidal wave theory. J Fluid Mech 1979:94, [1329-161].

[43] Rienecker M, Fenton J. A fourier approximation method for steady water waves. J Fluid Mech 1981;104:119-37. 
[44] Fenton JD. Numerical methods for nonlinear waves. Adv Coast Ocean Eng $1999 ; 5: 241-324$

[45] Pierson W, Moskowitz L. Aproposed spectral form for fully developed wind seas based on the similarity theory of s.a. kitaigorodskii, Tech. rep., U.S. Naval Oceanographic Office (1963).

[46] Hasselmann K, Barnett T, Bouws E, Carlson H, Cartwright D, Enke K, Ewing J, Gienapp H, Hasselmann D, Kruseman P, Meerburg A, Muller P, Olbers D, Richter K, Sell W, Walden H. Measurements of wind-wave growth and swell decay during the joint north sea wave project (jonswap). Tech. rep., Deutsches Hydrographisches Institut, Hamburg (1973).

[47] Bretschneider C. Wave variability and wave spectra for wind generated gravity waves. Tech. Memo 118, Beach ErosionBoard, US Army Corps of Engineering, Washington DC (1959).

[48] Ochi M, Hubble E. Six-parameter wave spectra, Coastal Engineering.

[49] Dommermuth D, Yue D. A high-order spectral method for the study of nonlinear gravity waves, Fluid mechanics.

[50] West BJ, Brueckner KA, Janda RS, Milder DM, Milton RL. A new numerical method for surface hydrodynamics. J Geophys Res: Oceans 1987;92(C11):11803-24, [URL: 〈http://dx.doi.org/10.1029/JC092iC11p11803〉. ].

[51] Bonnefoy F, Ducrozet G, Le Touz'e D, Ferrant P. AdvanceTime Domain Simulation of Nonlinear Water Waves Using Spectral Methods. In Advances in Numerical Simulation of Nonlinear Water Waves, Vol. 11, Advances in Coastal and Ocean Engineering, World Scientific, 2009, p. 129-164.

[52] Huang NE, Shen Z, Long SR, Wu MC, Shih HH, Zheng Q, Yen N-C, Tung CC, Liu $\mathrm{HH}$. The empirical mode decomposition and the hilbert spectrum for nonlinear and non-stationary time series analysis. Proc R Soc Lond A: Math, Phys Eng Sci 1998;454(1971):903-95.

[53] Fructurs D, Clamond D, Grue J, Kristiansen O. An efficient model for threedimensional surface wave simulation. part i: free space problems, Journal of computational physics.

[54] Clamond D, Fructurs D, Grue J, Kristiansen O. An efficient model for threedimensional surface wave ssimulation. Part II: Generation and absorption, Journal of computational physics.

[55] Falnes J. Ocean Waves and Oscillating Systems. Cambridge University Press; 2002.

[56] Cummins W. The impulse response function and ship motions 9 (Heft 47) (1962) 101-109.

[57] Rho JB, Choi HS, Shin HS, Park et al. IK. A study on mathieu-type instability of conventional spar platform in regular waves, International Journal of Offshore and Polar Engineering 15 (02).

[58] Paulling J, Rosenberg R. On unstable ship motions resulting from nonlinear coupling. J Ship Res 1959;3(1):36-46.

[59] Gomes R, Henriques J, Gato L, Falcão A. Testing of a small-scale floating owc model in a wave flume. In: International Conference on Ocean Energy, 2012, p. 17.

[60] Tarrant K, Meskell C. Investigation on parametrically excited motions of point absorbers in regular waves. Ocean Eng 2016;111:67-81.

[61] Moiseyev NN, Rumyantsev V. Dynamic stability of bodies containing fluid, 6 . Springer Science \& Business Media; 2012.

[62] Zhang Y, Zou Q-P, Greaves D. A device two-phase flow modelling of hydrodynamic performance of an oscillating water column device, Renewable Energy.

[63] Evans D, Porter R. Wave energy extraction by coupled resonant absorbers. Philos Trans R Soc A 2012;370(1959):315-44.

[64] Crowley S, Porter R, Evans DA. submerged cylinder wave energy converter with internal sloshing power take off. Eur J Mech - B/Fluids 2014;47:108-23, [enok Palm Memorial Volume URL: 〈http://www.sciencedirect.com/science/article/pii/ S0997754614000430 http://dx.doi.org/http://dx.doi.org/10.1016/j. euromechflu.2014.03.008)]

[65] Henry A, Schmitt P, Whittaker T, Rafiee A, Dias et al. F. The characteristics of wave impacts on an oscillating wave surge converter. In: Proceedings of the Twenty-third International Offshore and Polar Engineering Conference, International Society of Offshore and Polar Engineers, 2013.

[66] Harris R, Johanning L. Mooring systems for wave energy converters: A review of design issues and choices. Tech. rep. In: Proceedings of the 3rd International Conference on Marine Renewable Energy (MAREC), Newcastle, UK (2004).

[67] Johanning L, Smith G, Wolfran J.s Mooring design approach for wave energy converters, Journal of Engineering for the Maritime Environment.

[68] Johanning L, Smith G, Wolfran J. Measurements of static and dynamic mooring line damping and their importance for floating wec devices. Ocean Engineering.

[69] Orcina-Ltd., Orcaflex software, URL: 〈http://orcina.com/〉, [accessed 28.07.15] (2014)

[70] Johanning L, Smith G, Wolfran J. Interaction between mooring line damping and response frequency as a result of stiffness alteration in surge. In: Proceedings of the 25th international conference on offshore mechanics and arctic engineering (OMAE), Hamburg, 2006.

[71] Falcao AFdO. Wave energy utilization: A review of the technologies. Renewable and Sustainable Energy Reviews.

[72] Li Y, Yu Y. A synsthesis of numerical methods for modelling wave energy converter point-absorbers. Renewable and Sustainable Energy Reviews.

[73] Lagoun M, Benalia A, Benbouzid M. Ocean wave converters: State of the art and current status. In: IEEE International Energy Conference, p. 636-641, Manama., 2010.

[74] Bull D, Jacob P. Methodology for creating nonaxisymmetric wecs to screen mooring designs using a morison equation approach. In: Oceans, 2012, 2012, p. 1-9. http://dx.doi.org/10.1109/OCEANS.2012.6404870.
[75] M. WAMIT Inc., WAMIT v7.0 manual (2013).

[76] A. W. ANSYS Inc., AQWA manual Release 15.0 (2013).

[77] Delhommeau G. Seakeeping codes aquadyn and aquaplus. In: Proceedings of the 19th WEGEMT School on Numerical Simulation of Hydrodynamics:Ships and Offshore Structures, Nantes, 1993.

[78] Morris-Thomas MT, Irvin RJ, Thiagarajan KP. An investigation into the hydrodynamic efficiency of an oscillating water column. J Offshore Mech Arct Eng 2007;129(4):273-8.

[79] Sykes R, Lewis A, Thomas G. Predicting hydrodynamic pressure in fixed and floating owc using a piston model. In: Proceedings of the 9th European wave and tidal energy conference, Southampton, 2011.

[80] Faltinsen O. Sea Loads on Ships and Offshore Structures, Cambridge Ocean Technology Series. Cambridge University Press; 1993.

[81] Andersson J, Pedersen J. Capturing dynamic effects in ship tanks - a coupling between hydrod and openfoam 2011;65.

[82] Kapell J. Analysis of the inner flow in the wave energy converter wavetube.

[83] Armesto J, Guanche R, Ituriioz A, Vidal C, Losada I. Identification of state-space coefficients for oscillating water columns using temporal series, Ocean Engineering.

[84] Ituriioz A, Guanche R, Armesto J, Alves M, Vidal C, Losada I. Time-domain modelling of a fixed detached oscillating water column towards a floating mutltichamber device. Ocean Engineering.

[85] Zurkinden A, Ferri F, Beatty S, Kofoed J, Kramer M. Nonlinear numerical modelling and experimental testing of a point-absorber wave energy converter. Ocean Eng 2014;78:11-21.

[86] Giorgi G, Penalba M, Ringwood J. Nonlinear froude krylov force representation for heaving buoy wave energy converters. In: Proceedings of the Asian Wave and Tidal Energy Conference, Singapour, 2016.

[87] Bhinder M, Babarit A, Gentaz L, Ferrant P. Assessment of viscous damping via 3dcfd modelling of a floating wave energy device. In: Proceedings of the 9th European Wave and Tidal Energy Conference (EWTEC), Southampton, 2011.

[88] Giorgi G, Penalba M, Ringwood J. Nonlinear hydrodynamic force relevance for heaving point absorber and oscillating surge converters. In: Proceedings of the Asian Wave and Tidal Energy Conference, Singapour, 2016.

[89] Tao L, Dray D. Hydrodynamic performance of solid and porous heave plates. Ocean Eng 2008;35(10):1006-14, [URL /http://www.sciencedirect.com/science article/pii/S0029801808000589 http://dx.doi.org/http://dx.doi.org/10.1016/j. oceaneng.2008.03.003〉.].

[90] Tao L, Cai S. Heave motion suppression of a spar with a heave plate. Ocean En 2004;31(5-6):669-92, [URL 〈http://www.sciencedirect.com/science/article/pii/ S0029801803001732 http://dx.doi.org/http://dx.doi.org/10.1016/j.oceaneng. 2003.05.005〉.].

[91] Henry A, Schmitt P, Whittaker T, Rafiee A, Dias et al. F. The characteristics of wave impacts on an oscillating wave surge converter. In: Proceedings of the Twenty-third International Offshore and Polar Engineering Conference, International Society of Offshore and Polar Engineers, 2014.

[92] Wei Y, Abadie T, Henry A, Dias F. Wave interaction with an oscillating wave surge converter. part ii: Slamming. Ocean Eng 2016;113:319-34, [URL: 〈http://www. sciencedirect.com/science/article/pii/S0029801815007106 http://dx.doi.org/ http://dx.doi.org/10.1016/j.oceaneng.2015.12.041).].

[93] Henry A, Kimmoun O, Nicholson J, Dupont Wei GY, Dias F. A two dimensional experimental investigation of slamming of an oscillating wave surge converter. In: Proceedings of 24th International Society of Ocean and Polar Engineering (ISOPE), Busan, 2014.

[94] Falcão AF, Henriques JC, Cândido JJ. Dynamics and optimization of the owc spar buoy wave energy converter. Renew Energy 2012;48:369-81.

[95] Kramer M, Marquis L, Frigaard P. Performance evaluation of the wavestar prototype. In: Proceedings of the 9th European Wave and Tidal Energy Conference: EWTEC 2011, 2011.

[96] Fiévez J, Sawyer T. Lessons learned from building and operating a grid connected wave energy plant. In: Proceedings of the 11th European Wave and Tidal Energy Conference, Nantes, 2015.

[97] Mekhiche M, Edwards KA. Ocean power technologies power buoy: system-level design, development and validation methodology. In: Proceedings of the 2nd Marine Energy Technology Symposium. Seattle, WA, 2014.

[98] Mäki T, Mucha T, Vuorinen M. Waveroller one of the leading technologies for wave energy conversion. In: Proceedings of the 4th International Conference on Ocean Energy (ICOE), 2014.

[99] Drew B, Plummer A, Sahinkaya M. A review of wave energy converter technology, Journal of Power and Energy.

[100] Penalba M, Ringwood JV. A review of wave-to-wire models for wave energy converters. Energies 2016;9(7):506, [URL: 〈http://www.mdpi.com/1996-1073/ 9/7/506 http://dx.doi.org/10.3390/en9070506).].

[101] Takao M, Setoguchi T. Air turbines for wave energy conversion. Int J Rotating Mach 2012;2012:10

[102] A. Wells, Fluid driven rotatory transducer (1976).

[103] Falcão AFO, Gato LMC. Air turbines. in: A. Sayigh (Ed.), Comprehensive Renewable Energy, Elsevier, Oxford, 2012, p. 111-149. http://dx.doi.org/http:// dx.doi.org/10.1016/B978-0-08-087872-0.00805-2. http://www.sciencedirect. com/science/article/pii/B9780080878720008052.

[104] Falcão AFO, Henriques JCC. Oscillating-water-column wave energy converters and air turbines: a review. Renew Energy 2016;85:1391-424.

[105] Lopez I, Pereiras B, Castro F, Iglesias G. Optimisation of turbine-induced damping for an owc wave energy converter using a ras-vof numerical model, Applied Energy.

[106] Jelali M, Kroll A. Hydraulic servo-systems: modelling, identification and control. 
Springer Science \& Business Media; 2012

[107] Andersen TO, Hansen RH, Hansen A. Simulation of utilisation of pressure propagation for increased efficiency of secondary controlled discrete displacement cylinders. In: Fluid Dynamic and Mechanical \& Electrical Control Engineering, vol. 233 of Applied Mechanics and Materials, Trans Tech Publications, 2012, p. 36. http://dx.doi.org/10.4028/www.scientific.net/AMM.233.3.

[108] Hansen RH, Andersen TO, Pedersen HC, Hansen AH. Control of a 420 kn discrete displacement cylinder drive for the wavestar wave energy converter. In: ASME/ BATH 2014 Symposium on Fluid Power and Motion Control, American Society of Mechanical Engineers, 2014, pp. V001T01A021-V001T01A021.

[109] Hansen RH, Kramer MM, Vidal E. Discrete displacement hydraulic power take-off system for the wavestar wave energy converter. Energies 2013;6(8):4001-44.

[110] Ivantysyn J, Ivantysynova M. Hydrostatic pumps and motors: principles, design, performance, modelling, analysis, control and testing. New Delhi: Tech Books International; 2003.

[111] Crozier R. Optimisation and comparison of integrated models of direct-drive linear machines for wave energy convertion, [Ph.D. thesis], The University of Edinburgh (2013).

[112] Snnaper linear generator, http://www.snapperfp7.eu/home (2010)

[113] Crozier R, Bailey H, Mueller M, Spooner E, McKeever P, McDonald A. Analysis, design and testing of a novel direct-drive wave energy converter system. In: Proceedings of european wave and tidal energy conference (EWTEC), Southampton, 2011.

[114] Bailey H, Crozier R, McDonald A, Mueller M, Spooner E, McKeever. Hydrodynamic and electromechanical simulation of a snapper based wave energy converter. In: Proceedings on Industrial Electronics Conference (IECON), 2010.

[115] Davidson J, Giorgi S, Ringwood J. Numerical wave tank identification of nonlinear discrete time hydrodynamic models. In: Proceedings of the 1st International Conference on Renewable Energies Offshore (RENEW), Lisbon, 2014.

[116] Bhinder M, Mingham D, Cauxon D, Rahmati M, Aggidis G, Chaplin R. Numerical and experimental study of a surgin point-absorber wave energy converter. In: Procedings Proceedings of the 8th European Wave and Tidal Energy Conference (EWTEC), Uppsala, 2009.

[117] Vicente P, Falcao A, Justino P. A time-domain analysis of arrays of floating pointabsorber wave energy converters including the effect of nonlinear mooring forces. In: Proceedings of the 3rd International Conference on Ocean Energy (ICOE), 2010.

[118] Tanizawa K. The state of the art on numerical wave tank. in: Proceeding of 4th Osaka Colloquium on Seakeeping Performance of Ships, 2000

[119] Wackers J, Koren B, Raven HC, van der Ploeg A, Starke AR, Deng GB, Queutey P, Visonneau M, Hino T, Ohashi K. Free-surface viscous flow solution methods for ship hydrodynamics. Arch Comput Methods Eng 2011;18(1):1-41, [URL 〈http:// dx.doi.org/10.1007/s11831-011-9059-4)].

[120] Lin P, Liu P. Free surface tracking methods and their applications to wave hydrodynamics. Adv Coast Ocean Eng 1999;5:213-40.

[121] Queutey P, Visonneau M. An interface capturing method for free-surface hydrodynamic flows. Comput Fluids 2007;36(9):1481-510, [URL /http://www sciencedirect.com/science/article/pii/S0045793007000734 http://dx.doi.org/ http://dx.doi.org/10.1016/j.compfluid.2006.11.007〉.].

[122] Gentaz L, Alessandrini B, Delhommeau G. 2d nonlinear diffraction around free surface piercing body in a viscous numerical wave tank. In: Proceedings of the 9th international offshore and polar engineering conference, 1999.

[123] Hirt C, Nichols B. Volume of fluid (vof) method for the dynamics of free boundaries. Journal of Computational Physics.

[124] Iafrati A, Di Mascio A, Campana E. A level set technique applied to unsteady free surface flows. Int J Numer Methods Fluids 2001;35(3):281-97.

[125] Larsson L, Stern F, Bertram V. Benchmarking of computational fluid dynamics for ship flows: the gothenburg 2000 workshop. Journal of Ship Research. 47 (1) (2003), p. 63-81.

[126] Ferziger J, Peric M. Computational methods for fluid dynamics. Springer; 2002.

[127] CFD-Online, Turbulence modelling, URL: 〈http://www.cfd-online.com.http:// www.cfd-online.com/Wiki/Turbulence_modeling $\rangle$.

[128] Luo Y, Wang Z, Peng G, Xiao Y, Zhai L, Liu X, Zhang Q. Numerical simulation of a heave-only floating $\{\mathrm{OWC}\}$ (oscillating water column) device. Energy 2014;76:799-806, [URL: 〈http://www.sciencedirect.com/science/article/pii/ S0360544214010330 http://dx.doi.org/http://dx.doi.org/10.1016/j.energy. 2014.08.079)].

[129] Wei Y, Rafiee A, Henry A, Dias F. Wave interaction with an oscillating wave surge converter, part i: viscous effects. Ocean Eng 2015;104:185-203, [URL: 〈http:// www.sciencedirect.com/science/article/pii/S0029801815001705 http://dx.doi. org/http://dx.doi.org/10.1016/j.oceaneng.2015.05.002).].

[130] Schmitt P, Bourdier S, Whittaker T, Sarkar D, Renzi E, Dias F, Doherty K, van't Hoff et al. J. Hydrodynamic loading on a bottom hinged oscillating wave surge converter. In: Proceedings of the Twenty-second International Offshore and Polar Engineering Conference, International Society of Offshore and Polar Engineers, 2012.

[131] Yu Y-H, Li Y. Reynolds-averaged navier-stokes simulation of the heave performance of a two-body floating-point absorber wave energy system. Comput Fluids 2013;73:104-14, [URL: 〈http://www.sciencedirect.com/science/article/pii/ S0045793012003878 http://dx.doi.org/http://dx.doi.org/10.1016/j.compfluid. 2012.10.007〉.].

[132] Menter F, Kuntz M, Langtry R. Ten years of industrial experience with the sst turbulence model. Turbul, Heat Mass Transf 2003;4(1):625-32.

[133] El-Behery SM, Hamed MH. A comparative study of turbulence models performance for separating flow in a planar asymmetric diffuser. Comput Fluids 2011;44(1):248-57, [URL: 〈http://www.sciencedirect.com/science/article/pii/
S0045793011000168 http://dx.doi.org/http://dx.doi.org/10.1016/j.compfluid. 2011.01.009).].

[134] Chakrbarti S. Physical model testing of floating offshore structures. In: Dynamic Positioning Conference, 1998.

[135] Schmitt P, Whittaker T, Clabby D, Doherty K. The opportunities and limitations of using cfd in the development of wave energy converters, 2012, p. 89-97.

[136] École centrale de nantes (ecn), URL: 〈http://www.ec-nantes.fr/ $\rangle$.

[137] The environmental hydraulics institute (ih cantabria), URL: 〈http://www. ihcantabria.com/en/ $\rangle$.

[138] Ferrant P, Gentaz L, Monroy C, Luquet R, Dupont G, Ducrozet G, Alessandrini B, Jacquin E, Drouet A. Recent advances towards the viscous flow simulation of ships manouvering in waves. In: Proceedings of the 23rd International Workshop on Water Waves and Floating Bodies, Korea, 2008.

[139] Alessandrini B, Delhommeau G. Simulation of three-dimensional unsteady vicous free surface flow around a ship model. International journal for numerical methods in fluids.

[140] Alessandrini B, Delhommeau G. A fully coupled navier-stokes solver for calcuation of turbulent incompressible free surface flow past a ship hull, International journal for numerical methods in fluids.

[141] IHCantabria, Ih2vof code, URL: 〈http://ih2vof.ihcantabria.com/〉.

[142] Luquet R, Jacquin E, Guillerm P, Gentaz L, Ferrant P, Alessandrini B. Ranse with free surface computations around fixed and free dtmb 5415 model in still water and in waves. in: Proceedings of the CFD Workshop, Tokyo, 2005.

[143] Luquet R, Ferrant P, Alessandrini B, Ducrozet G, Gentaz L. Simulation of a tlp in waves overtopping of ruble mound breakwaters. In: Proceedings of International Society of Offshore and Polar Engineering (ISOPE), Lisbon, 2007.

[144] Losada I, Lara J, Christensen E, Garcia N. Modelling of velocity conv turbulence fields around and within low-crested rubble-mound breakwaters. Coastal Engineering.

[145] Lara J, Garcia N, Losada I. Rans modelling applied to random wave interaction with submerged permeable structures. Coastal Engineering.

[146] Losada I, Lara J, Guanche R, Gonzalez-Ondina J. Numerical analysis of wave overtopping of rubble mound breakwaters. Coastal Engineering.

[147] Rafiee A, Cummins S, Rudman M, Thiagarajan K. Comparative study on the accuracy and stability of $\{\mathrm{SPH}\}$ schemes in simulating energetic free-surface flows. Eur J Mech - B/Fluids 2012;36(0):1-16, [URL: 〈http://www.sciencedirect. com/science/article/pii/S0997754612000714 http://dx.doi.org/http://dx.doi. org/10.1016/j.euromechflu.2012.05.001).].

[148] Gingold RA, Monaghan JJ. Smoothed particle hydrodynamics: theory and application to non-spherical stars. Mon Not R Astron Soc 1977;181(3):375-89.

[149] Monaghan J. Theory and applications of smoothed particle hydrodynamics, in frontiers in numerical analysis. Heidelberg GERMANY: Springer; 2005. p. 143-93.

[150] Cleary PW, Prakash M, Ha J, Stokes N. Smooth particle hydrodynamics: status and future potential. Progress Comput Fluid Dyn, Int J 2007;7(2):70-90.

[151] Ulrich C, Leonardi M, Rung T. Multi-physics $\{\mathrm{SPH}\}$ simulation of complex marine-engineering hydrodynamic problems. Ocean Eng 2013;64:109-21, [URL: 〈http://www.sciencedirect.com/science/article/pii/S0029801813000875 http:// dx.doi.org/http://dx.doi.org/10.1016/j.oceaneng.2013.02.007/.].

[152] Monaghan J. Simulating free surface flows with sph. J Comput Phys 1994;110(2):399-406, [URL: 〈http://www.sciencedirect.com/science/article/pii/ S0021999184710345http://dx.doi.org/http://dx.doi.org/10.1006/jcph.1994. 1034).].

[153] Gomez-Gesteira M, Rogers BD, Dalrymple RA, Crespo AJ. State-of-the-art of classical sph for free-surface flows. J Hydraul Res 2010;48(sup1):6-27, [URL: 〈http://dx.doi.org/10.1080/00221686.2010.9641242 http://arxiv.org/abs/ http://dx.doi.org/10.1080/00221686.2010.9641242].

[154] Koshizuka S, Oka Y. Moving-particle semi-implicit method for fragmentation of incompressible fluid. Nucl Sci Eng 1996;123(3):421-34.

[155] Koh C, Gao M, Luo C. A new particle method for simulation of incompressible free surface flow problems. Int J Numer Methods Eng 2012;89(12):1582-604.

[156] Sampath R, Montanari N, Akinci N, Prescott S, Smith C. Large-scale solitary wave simulation with implicit incompressible sph. J Ocean Eng Mar Energy 2016;2(3):313-29.

[157] Monaghan J. Smoothed particle hydrodynamics and its diverse applications. Annu Rev Fluid Mech 2012;44:323-46.

[158] Hongbin J, Xin D. On criterions for smoothed particle hydrodynamics kernels in stable field. J Comput Phys 2005;202(2):699-709.

[159] Müller M, Charypar D, Gross M. Particle-based fluid simulation for interactive applications. In: Proceedings of the 2003 ACM SIGGRAPH/Eurographics symposium on Computer animation, Eurographics Association, 2003, p. 154-159.

[160] Yang Q, Jones V, McCue L. Free-surface flow interactions with deformable structures using an sph-fem model. Ocean Eng 2012;55:136-47, [URL: 〈http:// www.sciencedirect.com/science/article/pii/S0029801812002557 http://dx.doi. org/http://dx.doi.org/10.1016/j.oceaneng.2012.06.031).]

[161] Rafiee A, Elsaesser B, Dias F. Numerical simulation of wave interaction with an oscillating wave surge converter. In: ASME 2013 Proceedings of the 32nd International Conference on Ocean, Offshore and Arctic Engineering, American Society of Mechanical Engineers, 2013, p. V005T06A013-V005T06A013.

[162] Yeylaghi S, Buckham B, Moa B, Oshkai P, Beatty S, Crawford C. Sph modeling of hydrodynamic loads on a point absorber wave energy converter hull. In: Proceedings of the European Wave and Tidal Energy Conference, Nantes, France.

[163] Yeylaghi S, Moa B, Oshkai P, Buckham B, Crawford C. Isph modelling of an oscillating wave surge converter using an openmp-based parallel approach. J Ocean Eng Mar Energy 2016:1-12.

[164] Rafiee A. Sph modeling of multi-phase and energetic flows. [Ph.D. thesis], 
University of Western Australia (2012).

[165] Cummins SJ, Rudman M. An sph projection method. J Comput Phys 1999;152(2):584-607.

[166] Becker M, Teschner M. Weakly compressible sph for free surface flows. in: Proceedings of the 2007 ACM SIGGRAPH/Eurographics symposium on Computer animation, Eurographics Association, 2007, p. 209-217.

[167] Westphalen J, Greaves DM, Raby A, Hu ZZ, Causon DM, Mingham CG, Omidvar P, Stansby PK, Rogers BD. Investigation of wave-structure interaction using state of the art cfd techniques. Open J Fluid Dyn 2014.

[168] Crespo A, Domínguez J, Altomare C, Barreiro A, Gómez-Gesteira M. Oscillating water column wec modelling with a sph model. In: Proceedings of the 2nd Second Iberian Workshop Advances on Smoothed Particle Hydrodynamics, 2015.

[169] Edge B, Gamiel K, Dalrymple R, Hérault A, Bilotta G. Application of gpusph to design of wave energy. In: Proceedings of the 9th International SPHERIC Workshop, Paris, France, 2014, p. 342-347.

[170] Gilloteaux J-C. Mouvements de grande amplitude d'un corps flottant en fluide parfait. application a la recuperation de l'energie des vagues. [Ph.D. thesis], Ecole Centrale de Nantes (ECN) (2007).

[171] Giorgi G, Ringwood JV. Computationally efficient nonlinear froude-krylov force calculations for heaving axisymmetric wave energy point absorbers. J Ocean Eng Mar Energy 2016:1-13.

[172] Malenica JHS, Eatock Taylor R. Second-orfer water wave diffraction by an array of vertical cylinders.

[173] Newman J. Second-order diffraction in short waves.

[174] Letournel L, Ferrant P, Babarit A, Ducrozet G. Developpement d'un outil de simulation num['e]rique bas sur l'approcheweak-scatterer pour l'étude des systémes houlomoteurs en grands mouvements. In: Proceedings of the 13th Journées de l'Hydrodynamique, Chatou, France, 2012.

[175] Guerberg E. Numerical modeling of fully nonlinear interaction of ocean waves with a submerged moving body.

[176] Stephan FD, Grilli T. Philippe Guyenne, A fully nonlinear model for three dimensional overturning waves over an arbitrary bottom. International journal for numerical methods in fluids.

[177] Letournel L, Ferrant P, Babarit A, Ducrozet G, Harris JC, Benoit M, Dombre E. Comparison of fully nonlinear and weakly nonlinear potential flow solvers for the study of wave energy converters undergoing large amplitude motions. In: ASME 2014 Proceedings of the 33rd International Conference on Ocean, Offshore and Arctic Engineering, American Society of Mechanical Engineers, 2014.

[178] Monroy C, Ducrozet G, Bonnefoy F, Babarit A, Gentaz L, Ferrant et al. P. Rans simulations of a calm buoy in regular and irregular seas using the swense method. In: Proceedings of the Twentieth International Offshore and Polar Engineering Conference, International Society of Offshore and Polar Engineers, 2010.

[179] Paulsen BT, Bredmose H, Bingham HB. An efficient domain decomposition strategy for wave loads on surface piercing circular cylinders. Coast Eng 2014;86(0):57-76, [URL: 〈http://www.sciencedirect.com/science/article/pii/ S0378383914000155 http://dx.doi.org/http://dx.doi.org/10.1016/j.coastaleng. 2014.01.006).].

[180] Schmitt P, Windt C, Nicholson J, Elsässer B. Development and validation of a procedure for numerical vibration analysis of an oscillating wave surge converter. European Journal of Mechanics - B/Fluids.

[181] Morison J, O'Brien M, Johnson J, Schaaf S. The forces exerted by surface waves on pliles, Petroleum Trans., AIME. Vol. 189, p. 149-157.

[182] Ferri F, Kramer M, Pecher A. Validation of a wave-body interaction model by experimental tests. In: Procedings of the International Society Offshore and Polar Engineering (ISOPE), 2013.

[183] Molin B. Hydrodynamique des structures offshore. Editions Technip; 2002.

[184] Folley M, Whittaker T, Henry A. The performance of a wave energy converter in shallow water. In: Proceedings of the 6th European wave and tidal energy conference (EWTEC), Glasgow, Edinburgh, 2005.

[185] Lok K, Stallard T, Stansby P, Jenkins N. Optimisation of a clutch-rectified power take off system for a heaving wave energy device in irregular waves with experimental comparison. Int J Mar Energy 2014;8:1-16.

[186] Babarit A, Hals J, Muliawan M, Kurniawan A, Moan T, Krokstad J. Numerical benchmarking study of a selection of wave energy converters. Renew Energy 2012;41:44-63, [URL: 〈http://www.sciencedirect.com/science/article/pii/ S0960148111005672 http://dx.doi.org/http://dx.doi.org/10.1016/j.renene. 2011.10.002〉.].

[187] Beatty S, Buckham B, Wild P. Experimental comparison of self-reacting point absorber wec designs. In: Proceedings of the 10th European Wave and Tidal Conference, EWTEC, Aalborg, Denmark, 2013.

[188] Iturrioz A, Guanche R, Armesto JA, Vidal C, Losada Í. J. Experimentally calibrated time-domain numerical model for a fixed owc device. In: ASME 2013 Proceedings of the 32nd International Conference on Ocean, Offshore and Arctic Engineering, American Society of Mechanical Engineers, 2013, pp. V008T09A074V008T09A074.

[189] Davidson J, Giorgi S, Ringwood J. Linear parametric hydrodynamic models for wave energy converters identified from numerical wave tank experiments, Ocean Engineering.

[190] Ringwood J, Davidson J, Giorgi S. Optimising numerical wave tank tests for the parametric identification of wave energy device modelling. In: In ASME 2015 Proceedings of the 34th International Conference on Ocean, Offshore and Artic Engineering (OMAE2015), St. John's, Newfoundland, 2015.

[191] Ringwood J, Davidson J, Giorgi S. Numerical Modelling of Wave Energy Converters: State of the art techniques for single devices an arrays, Academic Press, Elsevier, 2016, Ch. Chapter 7: Identifying Models Using Recorded Data, pp. 123-147.

[192] Ljung L. System identification: theory for the user. Pearson Education; 1998.

[193] Nelles O. Nonlinear System Identification: From classical approaches to Neural Networks and Fuzzy Models, Springer-Verag, Berlin, 2001.

[194] Pearson R, Pottmann M. Grpa-box identification of block-oriented nonlinear models. Journal of Process Control.

[195] Pearson R, Ogunnaike BA. Identification and control using Volterra models. Springer Science \& Business Media; 2002.

[196] Giorgi S, Davidson J, Ringwood JV. Identification of wave energy device models from numerical wave tank datapart 2: data-based model determination. IEEE Trans Sustain Energy 2016;7(3):1020-7.

[197] Knott G, Flower J. Measurement of energy losses in oscillatory flow through a pipe exit. Appl Ocean Res 1980;2(4):155-64.

[198] Alves M, Sarmento A. A nonlinear and viscous analysis of the diffraction flow in owc wave power plants. In: Proceedings of the 16th International Offshore and Polar Engineering Conference (ISOPE), San Francisco, USA, 2006, p. 179-184.

[199] Luo Y, Nader J-R, Cooper P, Zhu S-P. Nonlinear 2d analysis of the efficiency of fixed oscillating water column wave energy converters. Renew Energy 2014:64:255-65.

[200] Teixeira PR, Davyt DP, Didier E, Ramalhais R. Numerical simulation of an oscillating water column device using a code based on navier-stokes equations. Energy 2013;61:513-30.

[201] Liu Z, Hyun B-S, Hong et al. K-y. Application of numerical wave tank to owc air chamber for wave energy conversion. In: Proceedings of the Eighteenth International Offshore and Polar Engineering Conference, International Society of Offshore and Polar Engineers, 2008.

[202] Rafiee A, Fiévez J. Numerical prediction of extreme loads on the ceto wave energy converter. In: Proceedings of the 11th European Wave and Tidal Energy Conference, Nantes, France, 2015.

[203] Mishra V, Beatty S, Buckham B, Oshkai P, Crawford C. Application of an arbitrary mesh interface for cfd simulation of an oscillating wave energy converter. in: Proceedings 11th Eur. Wave Tidal Energy Conference, 2015, p. 07B141-07B1410.

[204] Beatty SJ, Hall M, Buckham BJ, Wild P, Bocking B. Experimental and numerical comparisons of self-reacting point absorber wave energy converters in regular waves. Ocean Eng 2015;104:370-86, [URL: 〈http://www.sciencedirect.com/ science/article/pii/S0029801815002115 http://dx.doi.org/http://dx.doi.org/10. 1016/j.oceaneng.2015.05.027).].

[205] Yu Y-H, Li Y. Reynolds-averaged navier-stokes simulation of the heave performance of a two-body floating-point absorber wave energy system. Comput Fluids 2013;73:104-14, [URL: 〈http://www.sciencedirect.com/science/article/pii/ S0045793012003878 http://dx.doi.org/http://dx.doi.org/10.1016/j.compfluid. 2012.10.007).].

[206] Folley M, Whittaker T, Hoff Jv. The design of small seabed-mounted bottomhinged wave energy converter. In: Proceedings of the 7th European Wave and Tidal Energy Conference (EWTEC), Porto, 2007.

[207] Renzi E, Doherty K, Henry A, Dias F. How does oyster work? The simple interpretation of oyster mathematics. Eur J Mech-B/Fluids 2014;47:124-31.

[208] Chang Y-C, Chen D-W, Chow Y-C, Tzang S-Y, Lin C-C, Chen J-H. Theoretical analysis and sph simulation for the wave energy captured by a bottom-hinged owsc. J Mar Sci Technol 2015;23(6):901-8. 